\title{
PEDF Is a Novel Oligodendrogenic Morphogen Acting on the Adult SVZ and Corpus Callosum
}

\author{
Jiho Sohn, ${ }^{1}$ Vimal Selvaraj, ${ }^{2}$ Kouji Wakayama, ${ }^{1,3}$ Lori Orosco, ${ }^{1}$ Eunyoung Lee, ${ }^{1}$ Susan E. Crawford, ${ }^{4}$ Fuzheng Guo, ${ }^{1}$ \\ Jordan Lang, ${ }^{1}$ Makoto Horiuchi, ${ }^{1}$ Konstantinos Zarbalis, ${ }^{1}$ Takayuki Itoh, ${ }^{1}$ Wenbin Deng, ${ }^{1}$ and David Pleasure ${ }^{1}$ \\ ${ }^{1}$ Institute for Pediatric Regenerative Medicine, University of California, Davis, School of Medicine, Sacramento, California 95817, ${ }^{2}$ Department of Animal \\ Science, Cornell University, Ithaca, New York 14853, ${ }^{3}$ Department of Advanced Clinical Science and Therapeutics, Graduate School of Medicine, University \\ of Tokyo, Tokyo, 113-0033, Japan, and ${ }^{4}$ Department of Pathology, Northwestern University, Evanston, Illinois 60301
}

Pigment epithelium-derived factor (PEDF) is a serine protease inhibitor (serpin) protein with well established neuroprotective and anti-angiogenic properties. Recent studies have also shown that PEDF enhances renewal of adult subventricular zone (SVZ) neural precursors. In neurosphere cultures prepared from the SVZ of adult mice, we found that addition of recombinant PEDF to the medium enhanced expressions of oligodendroglial lineage markers (NG2 and PDGFr $\alpha$ ) and transcription factors (Olig1, Olig2, and Sox10). Similarly, continuous PEDF administration into the lateral ventricles of adult glial fibrillary acidic protein:green fluorescent protein (GFAP:GFP) transgenic mice increased the proportions of GFAP:GFP + and GFAP:GFP - SVZ neural precursors coexpressing oligodendroglial lineage markers and transcription factors. Notably, PEDF infusion also resulted in an induction of doublecortin- and Sox10 double-positive cells in the adult SVZ. Immunoreactive PEDF receptor was detectable in multiple cell types in both adult SVZ and corpus callosum. Furthermore, PEDF intracerebral infusion enhanced survival and maturation of newly born oligodendroglial progenitor cells in the normal corpus callosum, and accelerated oligodendroglial regeneration in lysolecithin-induced corpus callosum demyelinative lesions. Western blot analysis showed a robust upregulation of endogenous PEDF in the corpus callosum upon lysolecithin-induced demyelination. Our results document previously unrecognized oligodendrotrophic effects of recombinant PEDF on the adult SVZ and corpus callosum, demonstrate induction of endogenous CNS PEDF production following demyelination, and make PEDF a strong candidate for pharmacological intervention in demyelinative diseases.

\section{Introduction}

Glial fibrillary acidic protein-positive $(\mathrm{GFAP}+)$ neural precursors that reside in the subventricular zone (SVZ) in close proximity to endothelium and ependyma constitute a neurogenic niche in the adult forebrain (Shen et al., 2008; Danilov et al., 2009). These cells are capable of both self-renewal, driven by Notch signaling, and the generation of transit amplifying cells specified to neuronal and oligodendroglial lineages, driven by epidermal growth factor (EGF) receptor signaling (Morshead et al., 2003; Garcia et al., 2004; Menn et al., 2006; Aguirre et al., 2010). EGF intraventricular infusion enhances the generation of oligodendroglial progenitor cells (OPCs) from SVZ GFAP+ neural precursors, and accelerates remyelination of lysolecithin-induced corpus callosum demyelinative lesions (Gonzalez-Perez et al., 2009).

Received Feb. 9, 2012; revised June 11, 2012; accepted July 16, 2012

Author contributions: J.S., F.G., J.L., M.H., T.I., W.D., and D.P. designed research; J.S., V.S., K.W., L.O., E.L., F.G., M.H., and T.I. performed research; V.S., L.O., S.E.C., and K.Z. contributed unpublished reagents/analytic tools; J.S., V.S., K.W., L.O., E.L., S.E.C., F.G., J.L., M.H., K.Z., T.I., W.D., and D.P. analyzed data; J.S., K.W., E.L., F.G., M.H., K.Z., T.I., W.D., and D.P. wrote the paper.

This work was supported by NIH Grant R01 NS025044, National Multiple Sclerosis Society Grant RG 4397-A-5, The Shriners Hospitals for Children, and the California Institute for Regenerative Medicine Grant TG2-01163.

Correspondence should be addressed to David Pleasure, Institute for Pediatric Regenerative Medicine, University of California, Davis School of Medicine, c/o Shriners Hospitals for Children Northern California, 2425 Stockton Boulevard, Sacramento, CA 95817. E-mail: david.pleasure@ucdmc.ucdavis.edu.

DOI:10.1523/JNEUROSCI.0628-12.2012

Copyright $\odot 2012$ the authors $\quad 0270-6474 / 12 / 3212152-13 \$ 15.00 / 0$
In a search for additional SVZ niche factors that enhance formation of oligodendroglia in the adult forebrain, we evaluated the effects of pigment epithelium-derived factor (PEDF). PEDF is a neurotrophic, anti-angiogenic, and anti-tumorigenic member of the serine protease inhibitor (serpin) protein family (Tombran-Tink and Barnstable, 2003; Ek et al., 2006). PEDF has previously been reported to be secreted by adult SVZ endothelial and ependymal cells (Ramírez-Castillejo et al., 2006), as well as by astroglia and neurons (Sanagi et al., 2007; Yasuda et al., 2007), and to enhance self-renewal of adult murine SVZ precursor cells (Ramírez-Castillejo et al., 2006; Andreu-Agulló et al., 2009).

In the present study, we found that addition of PEDF to EGF/ basic fibroblast growth factor (bFGF)-containing culture medium elevated expression of Olig1/2, Sox10, and PDGFr $\alpha$ and numbers of GFAP:GFP + NG2 + cells in neurospheres derived from the SVZ of adult GFAP:green fluorescent protein (GFAP: GFP) transgenic mice, and did so without modulating cell proliferation. Corroborating these in vitro findings, PEDF intraventricular infusion increased numbers of GFAP:GFP+ cells coexpressing oligodendroglial markers in the adult SVZ. Interestingly, the oligodendroglial inductive effect of PEDF was also evident in SVZ GFAP:GFP - cells. Furthermore, PEDF infusion induced doublecortin (DCX)- and Sox10 double-positive cells in the adult SVZ. PEDF infusion also enhanced survival and maturation, but not mitotic cycling, of OPCs in the adult corpus callosum, and accelerated oligodendroglial regeneration in the 
lysolecithin-demyelinated corpus callosum. PEDF was robustly induced in corpus callosum after lysolecithin lesioning, suggesting a physiological role for PEDF in regulating oligodendroglial regeneration. Our studies are the first to report oligodendroglial morphogenic, survival, and remyelination-enhancing effects of PEDF.

\section{Materials and Methods}

Mice. Wild-type and GFAP:GFP transgenic mice (FVB/N-Tg (GFAPGFP)14Mes/J) (Zhuo et al., 1997) were purchased from The Jackson Laboratory. PEDF-null mice (Doll et al., 2003) were obtained from Northwestern University. Two- to 4-month-old male and female adult mice were used in this study. They were housed in a pathogen-free facility. All animal procedures were performed according to the Institutional Animal Care and Use Committee of the University of California Davis, and National Institutes of Health guidelines.

SVZ dissociation and neurosphere culture. SVZ tissue was microdissected from coronal slices of wild-type and GFAP:GFP transgenic mouse brains, minced with a razor blade, and incubated for $30 \mathrm{~min}$ at $37^{\circ} \mathrm{C}$ in HBSS medium (Invitrogen) containing 0.05\% trypsin (Invitrogen) and $60 \mathrm{U} / \mathrm{ml}$ DNase I (Sigma). Cell suspensions were generated by gentle trituration using a fire-polished Pasteur pipette and then centrifuged for $5 \mathrm{~min}$ at $400 \mathrm{~g}$. Single cells were resuspended and plated in noncoated culture flasks (BD Biosciences) containing neurosphere medium [DMEM/F12 (Invitrogen) supplemented with N2 (Invitrogen), B27 (Invitrogen), $20 \mathrm{ng} / \mathrm{ml}$ EGF (Millipore) and $20 \mathrm{ng} / \mathrm{ml}$ bFGF (R\&D Systems)]. The cultures were maintained at $37^{\circ} \mathrm{C}, 5 \% \mathrm{CO}_{2}$ and supplemented with growth factors every two $\mathrm{d}$ for $6 \mathrm{~d}$ to generate primary neurospheres. The spheres were then spun and enzymatically dissociated into single cells. The dissociated cells were plated at a density of 5 cells/ $\mu l$ in neurosphere medium in the absence or presence of $50 \mathrm{ng} / \mathrm{ml}$ PEDF (Bioproducts MD) to generate control or PEDFtreated secondary neurospheres.

Flow cytometry and fluorescence-activated cell sorting. Control and PEDF-treated secondary GFAP:GFP neurospheres were dissociated into single cells and positive GFP expression was determined using wild-type SVZ neurosphere cells as a negative control. For flow cytometric analysis of percentages of NG2+ cells within the GFAP:GFP + cell population, single cells dissociated from control and PEDF-treated secondary GFAP: GFP neurospheres were incubated with anti-NG2 antibody (1:500) for 20 min followed by incubation with goat anti-rabbit secondary antibody conjugated with allophycocyanin (1:1000, R\&D Systems) for $15 \mathrm{~min}$ at room temperature, and then analyzed using a Cyan flow cytometer (Dako). For fluorescence-activated cell sorting (FACS) isolation of GFP + NG2 - and GFP + NG2 + single cells, primary GFAP:GFP neurospheres were dissociated into single cells, immunolabeled for NG2 expression as described above, and isolated using a FACS Aria II (BD Biosciences). The FACS-isolated cells were plated at a density of 5 cells $/ \mu \mathrm{l}$ in neurosphere medium in the absence or presence of PEDF to generate secondary neurospheres.

Immunocytochemistry on neurospheres and FACS-isolated cells. For immunocytochemical characterization of wild-type control and PEDFtreated secondary neurospheres, the spheres were directly plated or mechanically dissociated into single cells before plating onto poly-Dlysine (PDL) (20 $\mu \mathrm{g} / \mathrm{ml}$, Sigma)-coated chamber slides (Nunc). After $1 \mathrm{~h}$, cells were fixed with $4 \%$ paraformaldehyde (PFA) for $15 \mathrm{~min}$, washed three times with PBS, and blocked in $8 \%$ normal goat serum in PBS for 30 min at room temperature. Cells were then incubated for $3 \mathrm{~h}$ at room temperature or overnight at $4^{\circ} \mathrm{C}$ with primary antibodies as follows: anti-nestin (1:250, Millipore), anti-NG2 (1:400, Millipore), anti-O4 (1: 200, Millipore), or anti-Tuj1 (1:400, Covance). Cells were washed three times with PBS, and then incubated with Alexa Fluor-conjugated secondary antibodies (1:800, Invitrogen) for $1 \mathrm{~h}$ at room temperature. For nestin and Tuj1 immunostaining, permeabilization was done with $0.1 \%$ Triton X-100 in PBS $(\mathrm{v} / \mathrm{v})$ for $10 \mathrm{~min}$ before blocking and primary antibody incubation. Stained cells were mounted with Prolong Gold containing 4',6'-diamidino-2-phenylindole dihydrochloride (DAPI; Invitrogen) and images were acquired using a Zeiss fluorescence microscope.

For differentiation assays of control and PEDF-treated secondary neurospheres derived from FACS-purified GFAP:GFP+NG2- or GFAP:
$\mathrm{GFP}+\mathrm{NG} 2+$ cells, the spheres were plated on PDL (20 $\mu \mathrm{g} / \mathrm{ml}$, Sigma $)$ and laminin ( $5 \mu \mathrm{g} / \mathrm{ml}$, Sigma)-coated chamber slides in differentiation medium (DMEM/F12 supplemented with N2 and B27 but without EGF, bFGF, or PEDF) for $3 \mathrm{~d}$. Cells were then fixed with $4 \%$ PFA and immunostained for NG2, O4, or Tuj1 as described above.

For validation of GFAP expression in GFAP:GFP + or GFAP:GFPcell fractions, GFP - and GFP + cells that had been FACS-isolated from GFAP:GFP neurospheres were plated on PDL-coated chamber slides for $1 \mathrm{~h}$ before fixation and GFAP immunostaining using anti-GFAP $(1: 1000$, Dako). The staining procedure was done in the same way as for the Tuj1 staining described above.

Proliferation assay in neurosphere cultures. To assess proliferation of GFAP:GFP + NG2 + cells, bromodeoxyuridine (BrdU; $10 \mu \mathrm{M})$ was added to control and PEDF-treated GFAP:GFP secondary neurospheres for $12 \mathrm{~h}$ before cell dissociation and NG2 labeling. FACS-purified $\mathrm{GFAP}+\mathrm{NG} 2+$ cells were plated on PDL-coated chamber slides for $1 \mathrm{~h}$ before fixation with $4 \%$ PFA. Cells were then permeabilized with $0.1 \%$ Triton X-100 in PBS (v/v) for 10 min and blocked with $8 \%$ normal goat serum in PBS $(\mathrm{v} / \mathrm{v})$ for $30 \mathrm{~min}$. DNA denaturation was done with $0.07 \mathrm{~N}$ $\mathrm{NaOH}$ for 10 min and cells were washed three times with PBS. Cells were then incubated with anti-BrdU (1:100, Dako) overnight at $4^{\circ} \mathrm{C}$. After primary antibody incubation, cells were washed three times with PBS and incubated with Alexa Fluor-conjugated secondary antibodies for $1 \mathrm{~h}$ at room temperature.

Control and PEDF-treated wild-type neurospheres were pulsed with BrdU for $12 \mathrm{~h}$ before plating on a PDL-coated chamber slide and fixation with $4 \%$ PFA. Staining was performed as described above. For Ki67 staining, control and PEDF-treated wild-type neurospheres were directly plated on PDL-coated chamber slides for $2-3 \mathrm{~h}$ and fixed with $4 \%$ PFA. Cells were permeabilized with $0.1 \%$ Triton X-100 in PBS (v/v) for 10 min before incubation with anti-Ki67 (1:400, Vector Labs) overnight at $4^{\circ} \mathrm{C}$ and Alexa Fluorconjugated secondary antibody for $1 \mathrm{~h}$ at room temperature.

$R N A$ isolation and reverse transcriptase-PCR. For RNA isolation, neurospheres were spun and lysed with RNA lysis buffer, and total RNA was extracted using an absolute microRNA prep kit (Stratagene). During RNA extraction, DNase I was included to prevent genomic DNA contamination. cDNA was synthesized from $0.5 \mu \mathrm{g}$ to $1 \mu \mathrm{g}$ of total RNA using oligo-dT primer and a Superscript III First-Strand cDNA synthesis kit (Invitrogen) in $20 \mu \mathrm{l}$ reactions. For detection of PEDF receptor, also known as patatin-like phospholipase domain-containing protein 2 (PNPLA2; also referred to as desnutrin; Notari et al., 2006), $2 \mu \mathrm{l}$ of cDNA was used as a template, and PCR amplification was conducted using AmpliTaq Gold PCR master mix (Applied Biosystems). The oligonucleotide primers for the PEDF receptor were: forward 5' ACAGTGTCCCCATTCTCAGG $3^{\prime}$; and reverse 5' TGGTGAAGGACACTGCACTC $3^{\prime}$. PCR conditions were as follows: $95^{\circ} \mathrm{C}$ for $5 \mathrm{~min}$; 30 or 36 cycles of $\left(95^{\circ} \mathrm{C}\right.$ for $15 \mathrm{~s}, 55^{\circ} \mathrm{C}$ for $15 \mathrm{~s}, 72^{\circ} \mathrm{C}$ for $\left.1 \mathrm{~min}\right) ; 72^{\circ} \mathrm{C}$ for $10 \mathrm{~min}$. The PCR products were resolved on a $2 \%$ agarose gel and photographed using a Kodak Gel Logic Digital Imaging System. For quantitative analysis of oligodendroglial lineage-associated mRNAs, real-time PCR was performed on a LightCycler 480 (Roche) using a SYBR Green qPCR kit (Roche) with the following parameters: $95^{\circ} \mathrm{C}$ for $5 \mathrm{~min}, 40$ cycles of $\left(95^{\circ} \mathrm{C}\right.$ for $10 \mathrm{~s}, 55^{\circ} \mathrm{C}$ for $20 \mathrm{~s}, 72^{\circ} \mathrm{C}$ for $\left.30 \mathrm{~s}\right)$. Each primer set showed a single peak in the melting curve analysis ensuring the absence of false signaling. Glyceraldehyde-3-phosphatase dehydrogenase (GAPDH) was used as an internal control for normalization of mRNA levels. The oligonucleotide primer sets used in this assay are listed as follows: Olig1 forward, 5' CTTGCTCTCTCCAGCCAAAC 3', reverse, 5' CAGAACTGGGAGTGGAGAGG 3'; Olig2 forward, 5' AGCAATGGGAGCATTTGAAG 3', reverse, 5' TTCCATATCGGGACTTTTGG 3'; Sox10 forward, 5' AGG CAGGAAGGGTTAGGGTA 3', reverse, 5' GCGGAGAAAGGATCAGAGTG 3'; PDGFr $\alpha$ forward, 5' TGGCATGATGGTCGATTCTA 3', reverse, 5' CGCTGAGGTGGTAGAAGGAG 3'; GAPDH forward, 5'ATTCAACGGCACAGTCAAGG 3', reverse, 5' TGGATGCAGGGATGATGTTC 3'.

PEDF in vivo infusion and lysolecithin lesioning. PEDF (Bioproducts MD) was dissolved in $0.9 \%$ saline and continuously administered (300 ng per day) into the lateral ventricle of adult GFAP:GFP (see Figs. 3, 6) or wild-type mice (see Fig. 5) for $7 \mathrm{~d}$ via mini-osmotic pumps (Alzet 1007D 


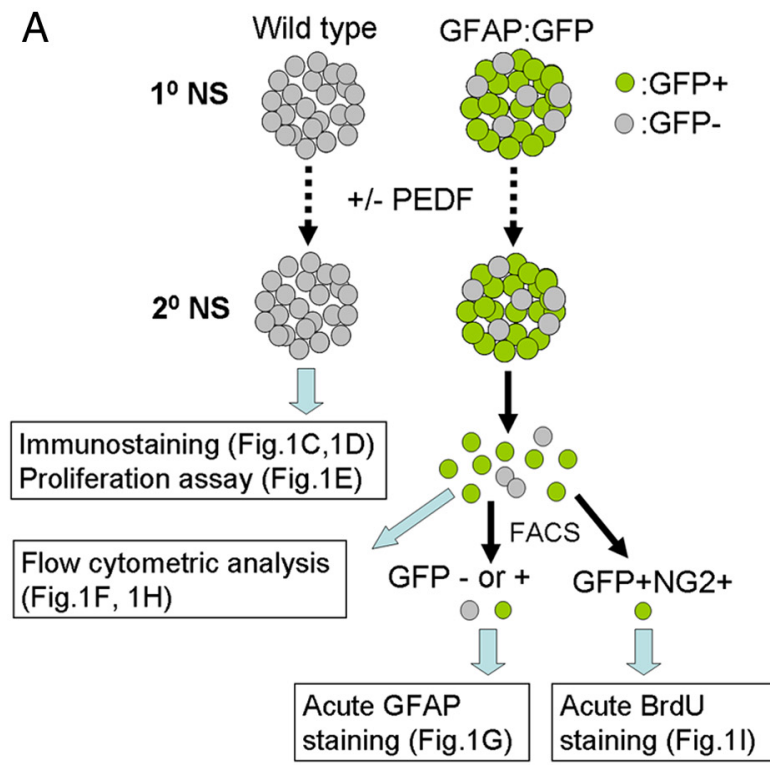

D

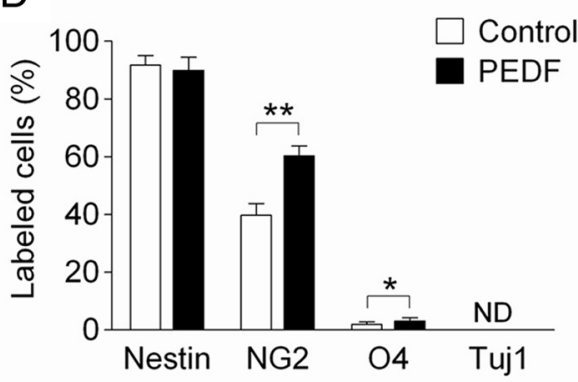

$\mathrm{F}$

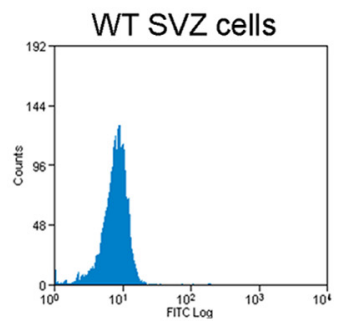

$\mathrm{E}$

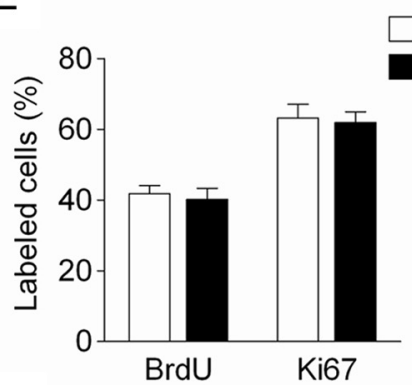

G

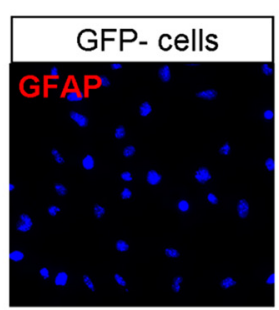

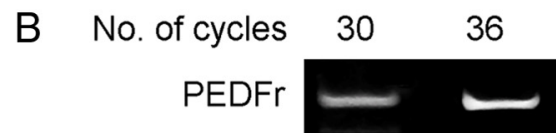
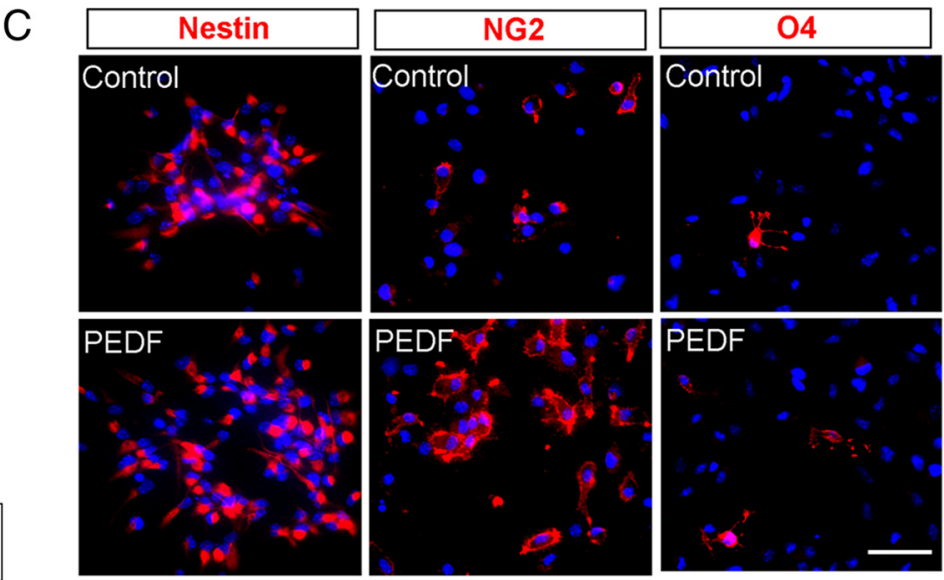

$\mathrm{H}$
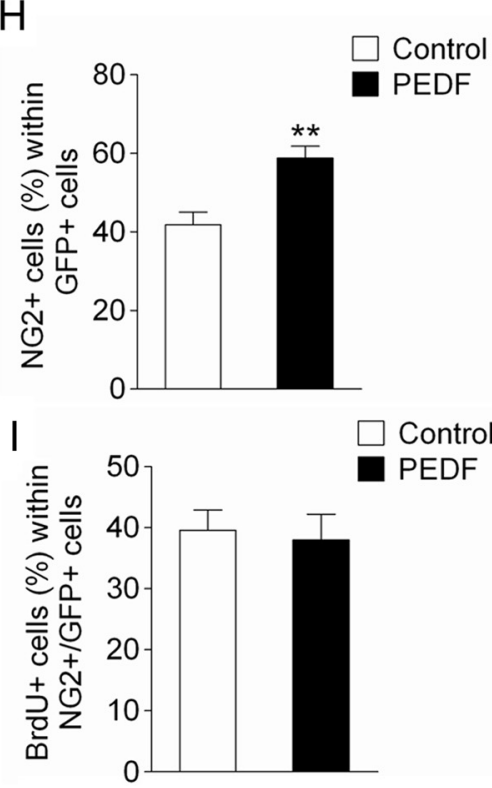

Figure 1. Characterization of control and PEDF-treated neurospheres derived from the SVZ of adult wild-type or GFAP:GFP transgenic mice. $\boldsymbol{A}$, Experimental flow chart. Secondary neurospheres derived from the SVZ of either adult wild-type or GFAP:GFP transgenic mice were grown in the absence or presence of PEDF ( $50 \mathrm{ng} / \mathrm{ml}$ ) for $5 \mathrm{~d}$, and then assayed as indicated. $\boldsymbol{B}$, RT-PCR analysis for expression of PEDF receptor in SVZ neurospheres. C, D, Wild-type control and PEDF-treated secondary neurosphere cells were immunostained for nestin, NG2, 04, or Tuj1. Immunostaining images $(\boldsymbol{C})$ and quantification data $(\boldsymbol{D})$ showing that PEDF significantly increased the numbers of NG2+ and $04+$ cells. $E$, Quantification of BrdU incorporation and Ki67 labeling in wild-type control and PEDF-treated secondary neurospheres. PEDF did not alter proliferation of neurosphere cells. F, FACS plots for GFP + and GFP - cell fractions dissociated from adult SVZ GFAP:GFP neurospheres. GFP + selection was set using wild-type SVZ neurospheres as a negative control. G, GFAP immunostaining acutely done on plated GFP + and GFP- cellsFACS-purified from GFAP:GFP neurospheres. $\boldsymbol{H}$, Graphic representation of flow cytometric quantification of percentages of NG2 + cells among GFP + cells in control and PEDF-treated secondary GFAP:GFP neurospheres, showing that PEDF promoted NG2 induction in GFP + cells. I, Quantification of BrdU incorporation among GFP + NG2 + cells FACS-purified from control and PEDF-treated secondary GFAP:GFP neurospheres, indicating that PEDF-mediated NG2 induction in GFAP:GFP + precursors was not due to selective proliferation of GFP + NG2 + cells. ND, Not determined. Results are means \pm SEM of three or four independent experiments. ${ }^{*} p<0.05,{ }^{* *} p<0.01$, Student's $t$ test. Scale bar, $30 \mu \mathrm{m}$.

and brain infusion kit \#3; Durect). Control animals received 0.9\% saline alone. Stereotaxic coordinates for cannula implantation of the pumps into the lateral ventricle were $0.2 \mathrm{~mm}$ posterior and $1.1 \mathrm{~mm}$ lateral to bregma, and $2.5 \mathrm{~mm}$ deep from the skull surface. For BrdU labeling of the SVZ (see Fig. 6), BrdU (100 mg/kg body weight, i.p.) was daily injected into adult GFAP:GFP transgenic mice during day 5-7 of intraventricular saline or PEDF infusion. For the BrdU labeling followed by PEDF infusion described below in Figures 7 and 8, adult wild-type mice first received $\mathrm{BrdU}(100 \mathrm{mg} / \mathrm{kg}$ body weight, i.p.) three times at $6 \mathrm{~h}$ intervals to label cycling OPCs in the corpus callosum. Twenty-four hours after the first injection, animals were either killed (see Fig. 7, day 0 ) or subjected to saline or PEDF infusion (300 ng per day) using mini-osmotic pumps into the corpus callosum for $9 \mathrm{~d}$ (see Fig. 7), or 2 or $5 \mathrm{~d}$ (see Fig. 8). The cannula was placed at the following coordinates for corpus callosum infusion: $0.2 \mathrm{~mm}$ posterior and $1.1 \mathrm{~mm}$ lateral to bregma, and $1.5 \mathrm{~mm}$ deep from the skull surface. For the experiment described below in Figure 8, EdU ( $100 \mathrm{mg} / \mathrm{kg}$ body weight, i.p.) was injected into the animals $5 \mathrm{~h}$ before they were killed to label proliferating cells.

For the lysolecithin-induced corpus callosum demyelination studies (see Fig. 9), $1 \mu \mathrm{l}$ of $1 \%$ lysolecithin (Sigma) was stereotaxically injected into the corpus callosum of adult mice at $0.2 \mathrm{~mm}$ posterior, $1.1 \mathrm{~mm}$ lateral to bregma, and $1.7 \mathrm{~mm}$ deep from the skull surface. Saline or 

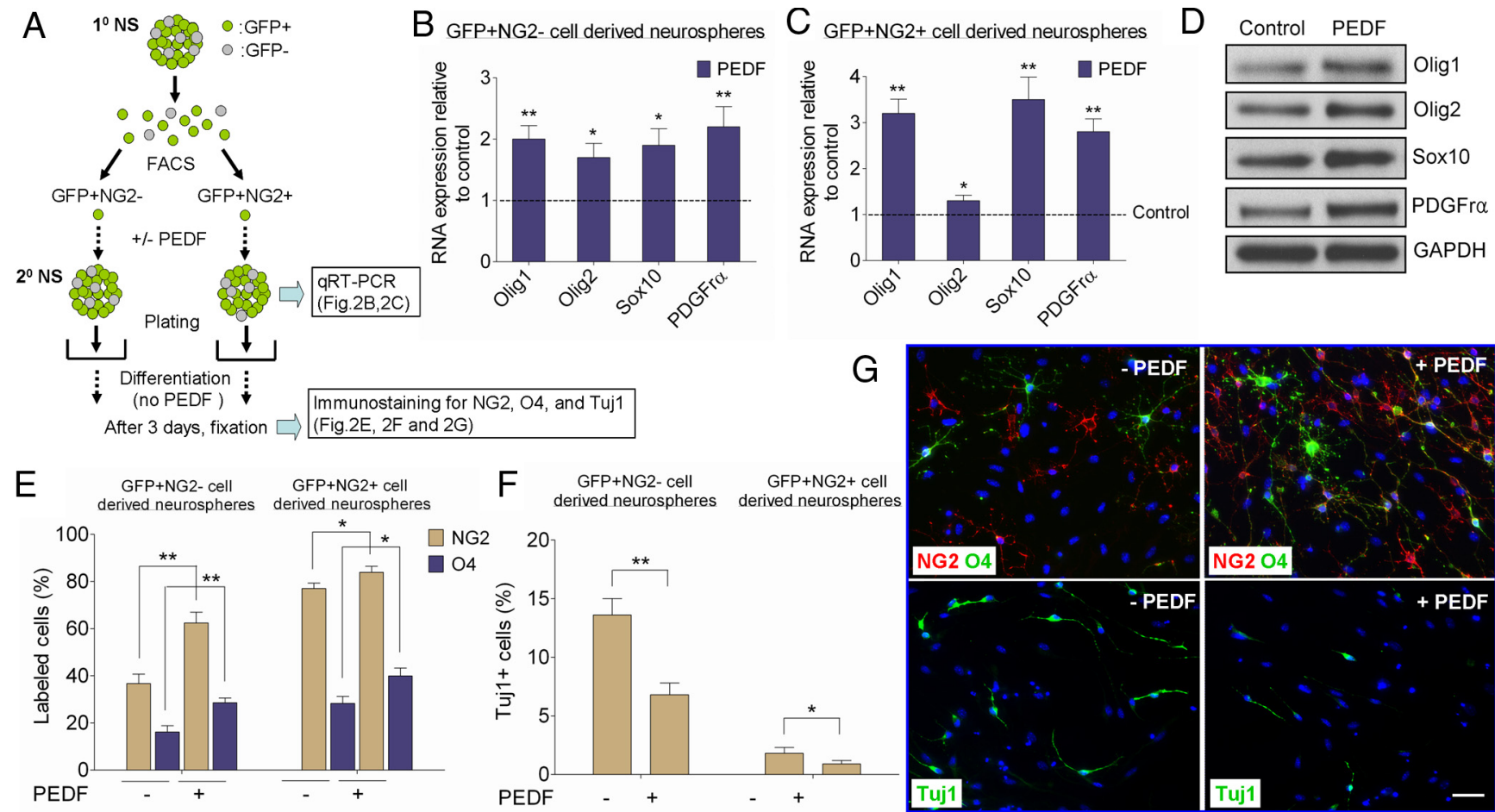

GFP+NG2+ cell

G
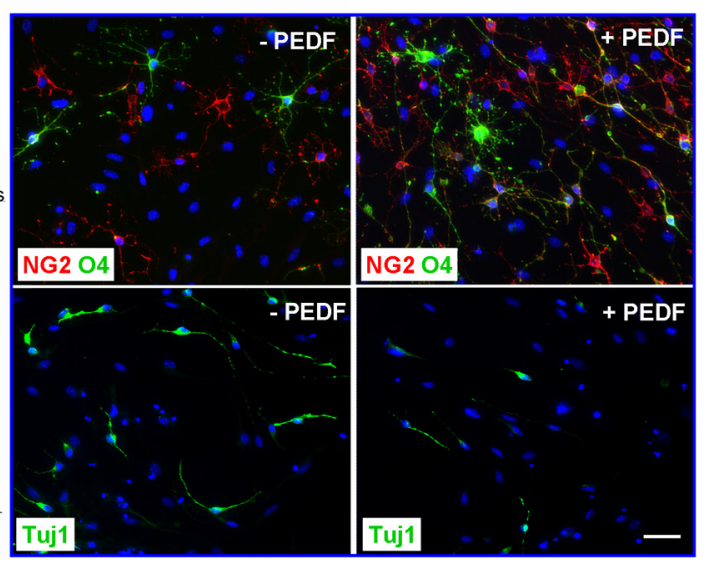

Figure 2. PEDF exerts oligodendrogenic effect on adult SVZGFAP + neural precursors. $A$, Experimental flow chart. GFAP:GFP +NG2 - and GFAP:GFP + NG2 + single cells were isolated by FACS from primary neurospheres derived from the SVZ of adult GFAP:GFP mice. Secondary neurospheres were then produced from these two FACS-purified populations in the absence or presence of PEDF $(50 \mathrm{ng} / \mathrm{ml})$. Assays were then performed as indicated. B, C, qRT-PCR analysis showing that PEDF elevated expression levels of oligodendroglial transcription factors and PDGFr $\alpha$ in both GFP + NG2 and GFP + NG2 + precursor-derived neurospheres. D, Western blot analysis of Olig1, Olig2, Sox10, and PDGFr $\alpha$ in control and PEDF-treated wild-type secondary neurospheres. $\mathbf{E}-\mathbf{G}$, Control and PEDF-treated secondary neurospheres derived from FACS-purified GFP + NG2 - or GFP + NG2 + subsets were plated in differentiation medium without mitogens or PEDF for $3 \mathrm{~d}$ before immunostaining for NG2, 04, or Tuj1. E, G, Greater numbers of NG2 + and 04+ oligodendroglial cells were produced from both GFP + NG2 - and GFP + NG2+ cell-derived neurospheres with PEDF treatment. $F, G, P E D F$ treatment resulted in diminished neuronal differentiation of GFP + NG2 - and GFP + NG2 + cell-derived neurospheres. $G$, Representative images of cells differentiated from control or PEDF-treated GFP + NG2 - cell-derived neurospheres. Results are means \pm SEM of three or four independent experiments. ${ }^{*} p<0.05$, and ${ }^{* *} p<0.01$, Student's ttest. Scale bar, $25 \mu$ m.

PEDF (300 ng per day) was then continuously infused via mini-osmotic pumps into the corpus callosum for 3 or $7 \mathrm{~d}$. The cannula was placed at the following coordinates for saline or PEDF intracerebral infusion: 0.2 $\mathrm{mm}$ posterior and $1.1 \mathrm{~mm}$ lateral to bregma, and $1.5 \mathrm{~mm}$ deep from the skull surface.

For Western blot analysis (see Fig. 10), $1 \mu \mathrm{l}$ of saline or $1 \%$ lysolecithin was stereotaxically injected into the corpus callosum of adult mice at 0.2 $\mathrm{mm}$ posterior, $1.1 \mathrm{~mm}$ lateral to bregma, and $1.7 \mathrm{~mm}$ deep from the skull surface. Corpus callosum tissues were harvested at 2, 5, or $7 \mathrm{~d}$ postinjection. PEDF (300 ng per day) was infused into the corpus callosum of intact, nonlesioned adult mice for $2 \mathrm{~d}$ at the following coordinates: 0.2 $\mathrm{mm}$ posterior and $1.1 \mathrm{~mm}$ lateral to bregma, and $1.5 \mathrm{~mm}$ deep from the skull surface.

Tissue preparation, immunohistochemistry, and quantification. After the saline or PEDF infusion, mice were anesthetized with ketamine (150 $\mathrm{mg} / \mathrm{kg}$ body weight, i.p.) and xylazine ( $16 \mathrm{mg} / \mathrm{kg}$ body weight, i.p.) injection, and transcardially perfused with PBS, followed by $4 \%$ PFA in PBS. Brain tissues were isolated and postfixed with $4 \%$ PFA in PBS overnight at $4{ }^{\circ} \mathrm{C}$, and washed with PBS. Tissues were then cryoprotected by sequential immersions in $15 \%$ and $30 \%$ sucrose solutions (v/v) before embedding in cryostat mounting medium (Tissue-Tek OCT, Sakura Finetek).

For immunostaining, cryostat tissue sections were air-dried at room temperature before blocking with $8 \%$ normal serum (v/v) and $0.1 \%$ Triton $\mathrm{X}-100(\mathrm{v} / \mathrm{v})$ in PBS for $1 \mathrm{~h}$ at room temperature. Sections were then incubated with primary antibodies overnight at $4^{\circ} \mathrm{C}$ in PBS containing $5 \%$ normal serum (v/v) and $0.1 \%$ Triton X-100 (v/v), followed by incubation with Alexa Fluor-conjugated secondary antibodies (1:800, Invitrogen) for $1 \mathrm{~h}$ at room temperature. Primary antibodies were used as follows: anti-GFP (1: 500, Rockland), anti-PDGFr $\alpha$ (1:200, BD Biosciences), anti-NG2 (1:300, Millipore), anti-Olig1 (1:500, Millipore), anti-Olig2 (1:100, R\&D Systems), anti-Sox10 (1:100, Santa Cruz Biotechnology), anti-BrdU (1:100, Santa
Cruz Biotechnology), anti-CC1 (1:200, Calbiochem), anti-CNP (1:500, Millipore), anti-MBP (anti-myelin basic protein; 1:200, Novus Biologicals), or anti-PNPLA2/PEDF receptor (1:20, R\&D Systems). Sections were mounted in Prolong Gold containing DAPI (Invitrogen). For BrdU immunostaining, tissue sections were treated with $2 \mathrm{~N} \mathrm{HCl}$ for $30 \mathrm{~min}$ at $37^{\circ} \mathrm{C}$ to denature DNA, followed by $10 \mathrm{~min}$ incubation with $0.1 \mathrm{~m}$ sodium borate, $\mathrm{pH} 8.5$ for neutralization. Subsequent immunostaining steps were performed as described above. EdU staining was performed by using Click-iT EdU assay kit (Invitrogen) following the manufacturer's instructions. TUNEL (terminal deoxynucleotidyl transferase dUTP nick end labeling) staining was performed by using DeadEnd TUNEL assay kits (Promega) following the manufacturer's instructions. For BrdU/TUNEL double labeling, TUNEL staining was performed first, and tissues were then fixed for 8 min with $4 \%$ PFA followed by BrdU staining as described above. For TUNEL/Olig2 and TUNEL/NG2 + staining, Olig2 or NG2 immunolabeling was first performed, followed by TUNEL staining.

All fluorescent images were captured by laser scanning confocal microscopy (Nikon C1) and projected with 5 - to 6 - $\mu$ m-thick $Z$-series stacks (Nikon EZ-C1 software). For quantifications, at least 10 coronal sections were analyzed for each marker, and cells were identified by their DAPIlabeled nuclei. Cell counts were performed in the dorsal corner of the SVZ (see Figs. 3, 6), with the total number of cells analyzed ranging between 998 and 1484, in the ipsilateral corpus callosum (see Figs. 7, 8), and in the lesion core determined by MBP immunostaining and cortical needle tract (see Fig. 9).

Western blot analysis. Control and PEDF-treated secondary neurospheres derived from the SVZ of adult wild-type mice (see Fig. 2) and corpus callosum tissues (see Fig. 10) were collected and lysed in a radioimmunoprecipitation assay buffer containing protease inhibitors (Thermo Fisher Scientific). Protein concentration was determined by BCA assay (Thermo Fisher Scientific). Protein separation was done on 


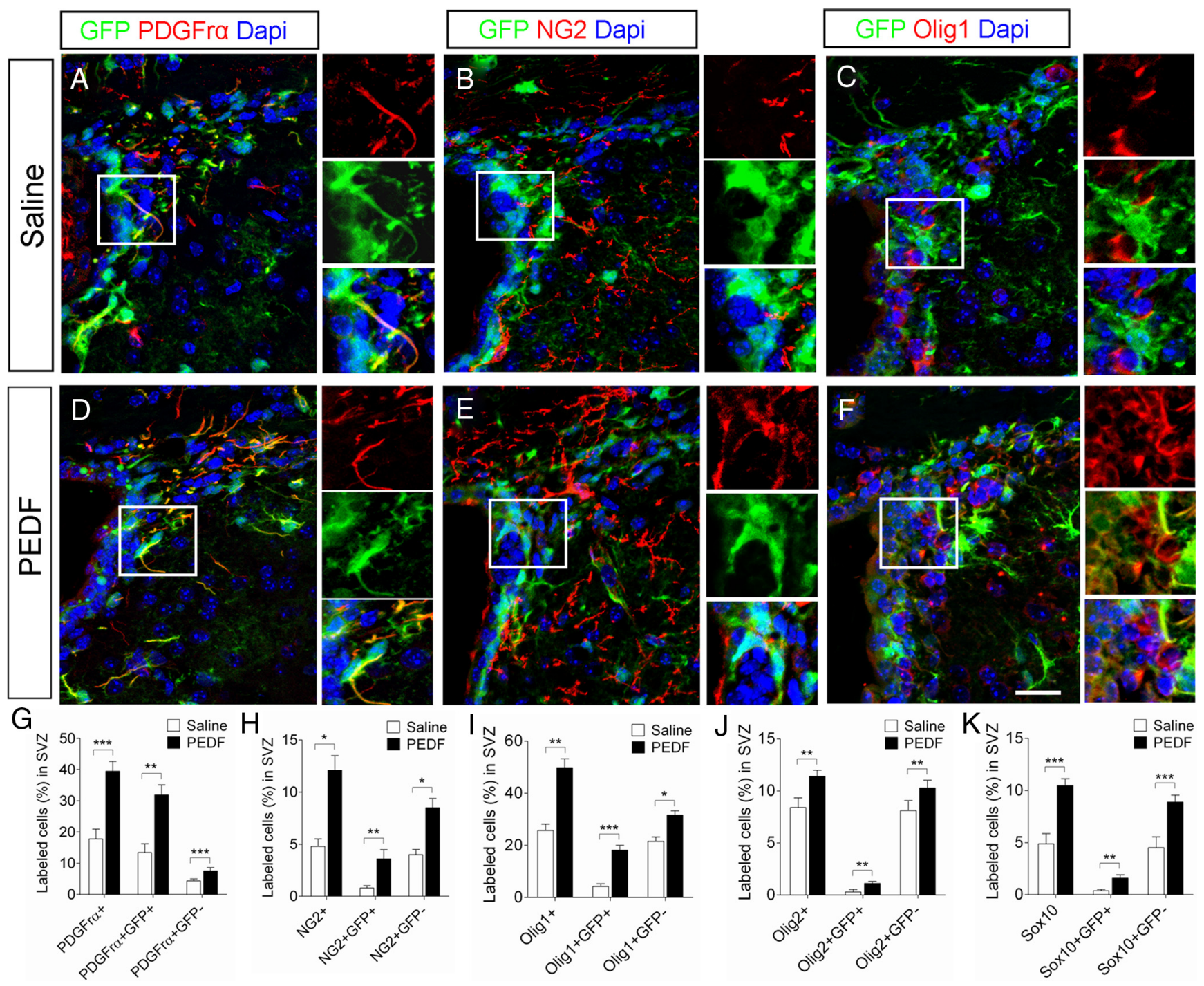

Figure 3. PEDF infusion increases the numbers of SVZ cells expressing early oligodendroglial lineage markers or oligodendroglial transcription factors. Saline or PEDF (300 ng per day) was administered via osmotic pump into the lateral ventricle of adult GFAP:GFP transgenic mice for $7 \mathrm{~d}$. The SVZ tissues were double-immunostained for GFP and markers for early oligodendroglial lineage (PDGFr $\alpha$ or NG2) or oligodendroglial transcription factors (Olig1, 0lig2, or Sox10). $\boldsymbol{A}-\boldsymbol{F}$, Confocal images of coronal sections of saline- and PEDF-infused SVZ immunolabeled with antibodies against GFP and PDGFr $\alpha$, NG2, or Olig1. Insets show magnified images of areas indicated by rectangles. Scale bar, $30 \mu \mathrm{m}$. G-K, Percentages of DAPI+ nuclei labeled with PDGFr $\alpha+$, PDGFr $\alpha+$ GFP +, and PDGFr $\alpha+$ GFP - (G), NG2+, NG2+GFP+, and NG2+GFP - (H), 0lig1+, 0lig1+GFP +, and 0lig1+GFP - (I), 0lig2+, 0lig2+GFP+, and 0lig2+GFP - (J), and Sox10 +, Sox10 + GFP +, and Sox10 + GFP- $(\boldsymbol{K})$ in the saline- and PEDF-infused SVZ. PEDF administration increased the proportions of both GFP + and GFP - cells coexpressing these oligodendroglial markers or transcription factors. Results are means \pm SEM $\left(n=4-5\right.$ brains). ${ }^{*} p<0.05,{ }^{*} p<0.01$, and ${ }^{* * *} p<0.005$, Student's $t$ test.

SDS polyacrylamide gels (Invitrogen) and transferred to PDVF membranes (Millipore). Membranes were blocked and then incubated with primary antibodies: Olig1 (1:3000, Millipore), Olig2 (1:3000, R\&D Systems), Sox10 (1:1000, Millipore), PDGFr $\alpha$ (1:500, Santa Cruz Biotechnology), and PEDF (1:100, R\&D Systems). Protein bands were detected using ECL (Thermo Fisher Scientific) with horseradish peroxidaseconjugated secondary antibodies (1:5000, GE Healthcare Life Sciences). Protein loading was determined by using antibody against GAPDH (1: 5000, Millipore).

Statistical methods. Paired comparisons were analyzed by two-tailed Student's $t$ tests, with $p<0.05$ required for statistical significance.

\section{Results}

PEDF treatment increases the proportion of NG2+ cells in adult SVZ neurospheres

To examine the effect of PEDF on cellular phenotypes within neurospheres, secondary neurospheres derived from the SVZ of adult wild-type mice were grown in the absence or presence of PEDF for $5 \mathrm{~d}$. These control and PEDF-treated secondary neuro- spheres were then subjected to immunocytochemical characterization and proliferation assay (as illustrated in Fig. $1 \mathrm{~A}$ ). We first confirmed PEDF receptor (PEDFr) mRNA expression in the secondary neurospheres by reverse transcriptase PCR (RT-PCR) analysis (Fig. $1 \mathrm{~B}$ ). Before immunostaining, control and PEDFtreated neurospheres were directly plated, or mechanically dissociated into single cells, and then plated onto PDL-coated chamber slides. Approximately $90 \%$ of the cells in both control and PEDF-treated neurospheres were positive for nestin, a marker for neural precursors (Frederiksen and McKay, 1988; Doetsch et al., 1997) (Fig. 1C,D), indicating the vast majority of cells within the neurospheres were at precursor stage. Interestingly, PEDF treatment increased the proportion of cells that expressed the OPC surface marker NG2 (Aguirre and Gallo, 2004) (Fig. 1C,D). Although present at low density, cells expressing the immature oligodendroglial surface marker O4 (Sohn et al., 2006) were also significantly more frequent in PEDF-treated $(3.1 \%)$ 


\section{PEDFr GFAP:GFP}

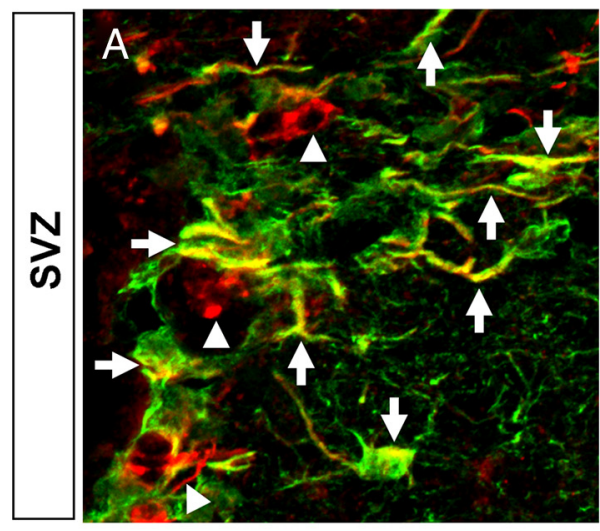

PEDFr DCX Dapi

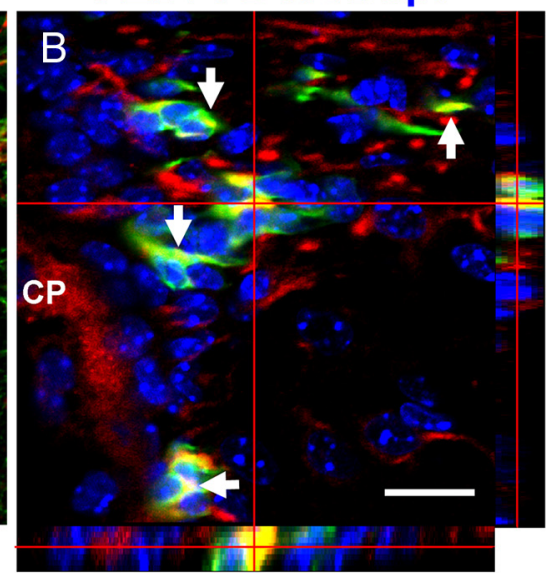

PEDFr Dapi

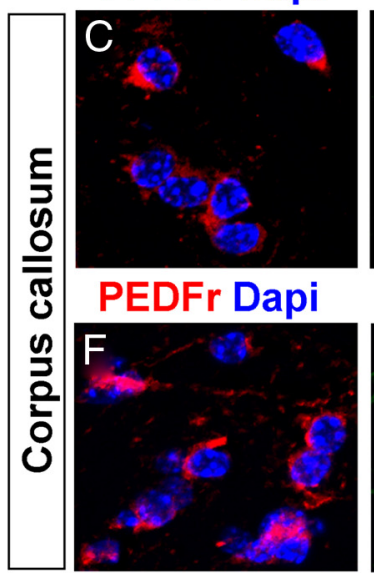

Olig2

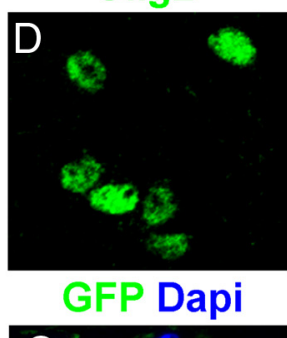

Merge

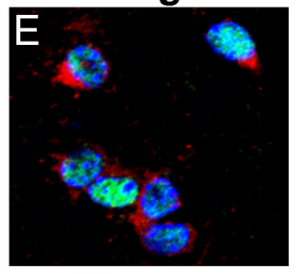

Merge

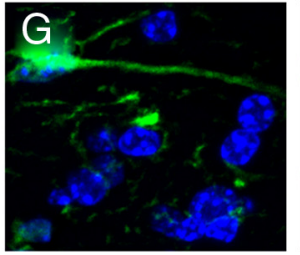

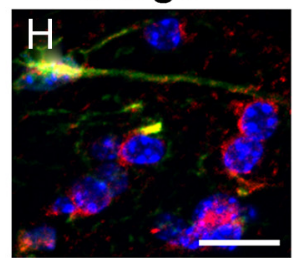

Figure 4. Immunohistochemical analysis of PEDF receptor expression in the adult SVZ and corpus callosum. $A$, Confocal image showing expression of PEDF receptor in GFAP:GFP + (arrows) and GFAP:GFP - cells (arrowheads) in the SVZ. B, DCX + neuroblasts (indicated by arrows and orthogonal view) in the SVZ expressed PEDF receptor. (P, Choroid plexus. Scale bar, $25 \mu \mathrm{m}$. C $-\boldsymbol{H}$, PEDF receptor expression was detected in both 0lig2 + oligodendroglial lineage cells $(\boldsymbol{C}-\boldsymbol{E})$ and GFAP:GFP + astrocytes $(\boldsymbol{F}-\boldsymbol{H})$ in the adult corpus callosum. Scale bar, $20 \mu \mathrm{m}$.

than in control $(2.0 \%)$ neurosphere cells (Fig. 1C,D). Tuj1 + cells were rarely present in both control and PEDF-treated neurosphere cells (Fig. 1D). PEDF treatment did not alter the proportions of cells labeled with BrdU or expressing the proliferative marker Ki67 (Fig. 1E). These initial secondary neurosphere analyses suggested a role for PEDF in enhancing oligodendroglial lineage specification of SVZ neural precursors.

\section{PEDF enhances NG2 induction}

\section{among adult SVZ GFAP:GFP+ neurosphere cells}

To further characterize the oligodendrogenic effect of PEDF on SVZ GFAP + neural precursors, we used neurospheres prepared from the SVZ of adult GFAP:GFP transgenic mice. Secondary GFAP:GFP neurospheres cultured in the absence or presence of PEDF were dissociated into single cells and analyzed as illustrated in Figure $1 A$. This transgenic animal model has been well characterized in previous studies showing that GFP reporter expression reliably identifies GFAP + cells (Zhuo et al., 1997; Pastrana et al., 2009; Platel et al., 2009). To verify the specificity of GFP expression in our cultures, GFP + and GFP - cell fractions were isolated from secondary GFAP:GFP neurospheres by FACS, plated, and subjected to GFAP immunostaining (Fig. 1F, G). Close to $80 \%$ of the neurosphere cells were GFP+ (Fig. $1 F)$ and
GFAP immunoreactivity was specific to GFP + cell fractions (Fig. 1G). PEDF treatment induced a substantial increase in the proportion of $\mathrm{NG} 2+$ cells within the GFAP:GFP + cell fraction (Fig. $1 H$ ) without altering their proliferation (Fig. 1I). Activated caspase 3 immunostaining indicated that cell death was very infrequent in both control and PEDF-treated neurospheres maintained in EGF- and bFGF-containing growth medium (data not shown). Thus, the increase in number of NG2 +/GFAP:GFP + cells in the PEDFtreated neurosphere is likely to have been mainly attributable to an oligodendroglial lineage inductive action of PEDF on the SVZ GFAP + cells.

\section{Target specificity of PEDF within SVZ GFAP:GFP + neurospheres}

To explore the target specificity of PEDF, we FACS-separated GFAP:GFP+ cells from primary GFAP:GFP SVZ neurospheres into two subtypes based on their NG2 expression, considering GFAP:GFP+/NG2 - cells as neural precursors not specified to the oligodendroglial lineage, and GFAP:GFP+/NG2+ cells as precursors specified to the oligodendroglial lineage. As depicted in Figure 2A, FACS-isolated GFP+NG2- and GFP+ $\mathrm{NG} 2+$ cells were cultured in the absence or presence of PEDF for $5 \mathrm{~d}$ to generate secondary neurospheres. Our plating density of FACS-purified cells was low (i.e., 5 cells/ $\mu \mathrm{l}$ ) to favor clonal generation of neurospheres. Control and PEDF-treated secondary neurospheres were then subjected to quantitative RT-PCR (qRT-PCR; Fig. $2 B, C$ ), or plated on PDL- and laminin double-coated chamber slides in the absence of EGF, bFGF, and PEDF for $3 \mathrm{~d}$ before performing NG2, O4, or Tuj1 immunostaining (Fig. $2 E-G$ ). qRT-PCR results showed that PEDF elevated steady-state levels of mRNAs encoding Olig1, Olig2, and Sox10, transcription factors characteristic of the oligodendroglial lineage (Lu et al., 2001; Zhou et al., 2001; Finzsch et al., 2008; Pozniak et al., 2010), as well as for the OPC marker PDGFr $\alpha$ (Jackson et al., 2006; Rivers et al., 2008), in both $\mathrm{GFP}+\mathrm{NG} 2-$ and GFP + NG2 + cell-derived neurospheres (Fig. $2 B, C)$. Western blot analysis of control and PEDF-treated secondary neurospheres derived from the SVZ of wild-type mice further confirmed PEDF-induced elevation of these oligodendroglial markers at protein levels (Fig. 2D). Differentiation assays showed that GFP + NG2 + cells had substantially greater oligodendrogenic potential than GFP+NG2- cells (Fig. 2E). Importantly, PEDF treatment increased the numbers of $\mathrm{NG} 2+$ and $\mathrm{O} 4+$ oligodendroglial lineage cells (Fig. 2E, G), but reduced the number of Tuj1+ neurons (Fig. $2 F, G$ ) differentiated from both GFP+NG2- and GFP+NG2+ cellderived neurospheres. In particular, the oligodendrogenic effect of PEDF on GFP + NG2 - cell-derived neurospheres argued that PEDF enhances specification of adult SVZ GFAP+ cells to the oligodendroglial lineage. 
PEDF enhances the expressions of oligodendroglial markers and transcription factors in the adult SVZ To assess the effects of PEDF on oligodendroglial specification of SVZ cells in vivo, we continuously infused saline or PEDF into the ventricular system of adult GFAP: GFP transgenic mice for $7 \mathrm{~d}$. In the salineinfused control mice, $17.8 \%$ of total SVZ cells were positive for PDGFr $\alpha$ (Fig. $3 A, G$ ) and $4.8 \%$ were positive for NG2 (Fig. $3 B, H$ ). The proportions of both PDGFr $\alpha+$ (Fig. 3D,G) and NG2+ (Fig. 3E,H) cells were markedly increased (39.5\% and $12.1 \%$, respectively) in the PEDF-infused SVZ. We also immunostained saline- and PEDF-infused SVZ sections for the oligodendroglial transcription factors Olig1, Olig2 and Sox10. PEDF infusion increased the percentages of SVZ cells immunoreactive for these transcription factors, further confirming the pro-oligodendroglial effect of PEDF in vivo (Fig. $3 C, F, I-K$ ). This PEDF effect was evident in both GFP+ and GFP- cells as demonstrated by increased proportions of GFP + and GFP - cells coexpressing oligodendroglial markers, suggesting that PEDF may act on multiple cell types in the SVZ.

PEDF induces oligodendroglial phenotype in SVZ neuroblasts Immunohistochemical analysis revealed that PEDFr was ubiquitously expressed in the adult SVZ including in GFAP + cells (Fig. $4 A$ ) and early neuronal lineage cells (Fig. $4 B$ ) immunoreactive for DCX, an established maker for SVZ neuroblasts (Brown et al., 2003; Lagace et al., 2007; Jablonska et al., 2010). To examine oligodendroglial induction in SVZ neuroblasts by PEDF, we double-immunostained the SVZ of saline- or PEDF-infused wild-type mice for DCX and Sox10. In the salineinfused control SVZ, we did not observe $\mathrm{DCX}+$ neuroblasts that coexpressed Sox10 (Fig. 5A,B), whereas DCX $+/$ Sox $10+$ cells were present in the PEDF-infused SVZ (Fig. $5 C, D)$. Together, our results indicate that PEDF promotes oligodendroglial lineage specification of both GFAP + neural precursors and DCX + neuroblasts. Consistent with the lack of detection of a mitogenic effect of PEDF on neurosphere cells, total numbers of BrdU+ cells (Fig. 6A,B,E) and of BrdU+/GFAP:GFP+ cells (Fig. 6C,D,F) were not altered by $P E D F$ perfusion, further supporting an oligodendroglial inductive effect of PEDF.

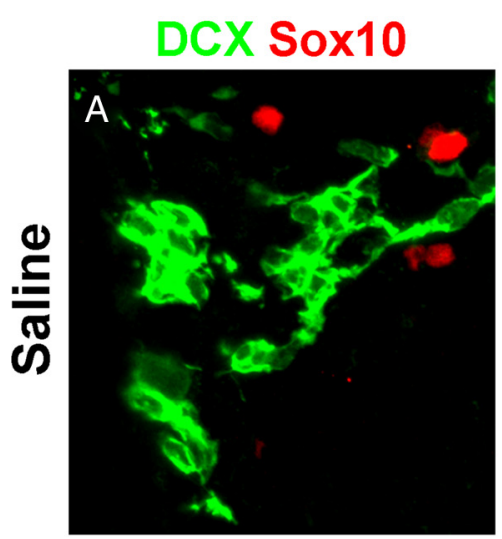

\section{Merge with Dapi}
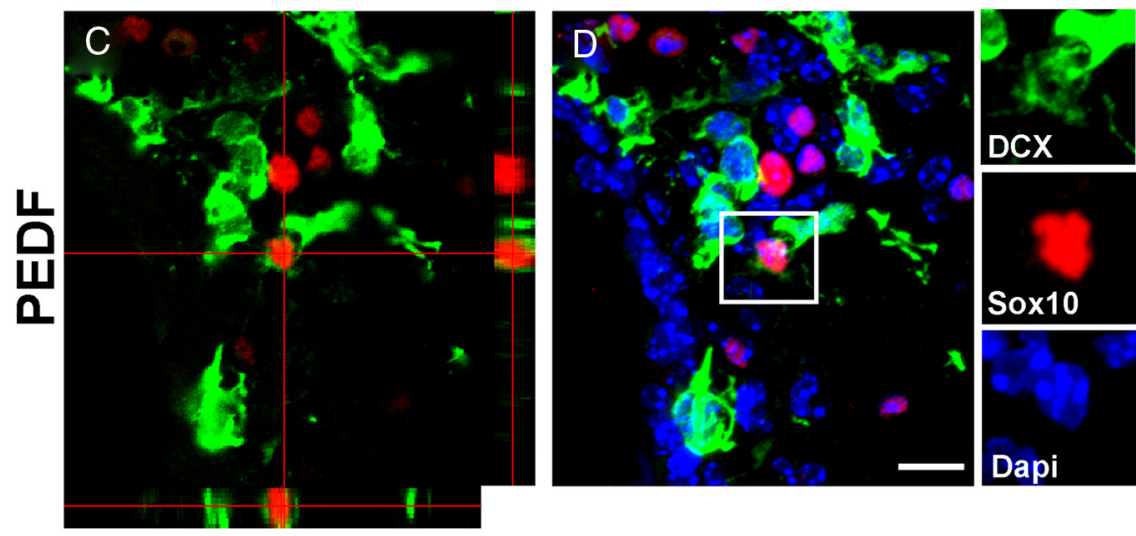

Figure 5. PEDFinduces DCX +/Sox $10+$ cells intheadultSVZ.Salineor PEDF $(300 \mathrm{ng} / \mathrm{ml})$ wasinfused intothelateral ventricleofadultwild-type mice for $7 \mathrm{~d}$ before the animals were killed. $A, B$, Confocal images of saline-infused SVZ double-immunostained for DCX and Sox 10. № DCX+ cells expressed Sox10 in the SVZ.C, $\boldsymbol{D}$, Orthogonal ( $\boldsymbol{C}$ andZ-series stack ( $\boldsymbol{D}$ ) confocal images of PEDF-infused SVZ. PEDFinfusion induced DCX + / Sox10+ cells in the SVZ. The insets in D show magnified images for the area indicated by a rectangle. Scale bar, $20 \mu \mathrm{m}$.
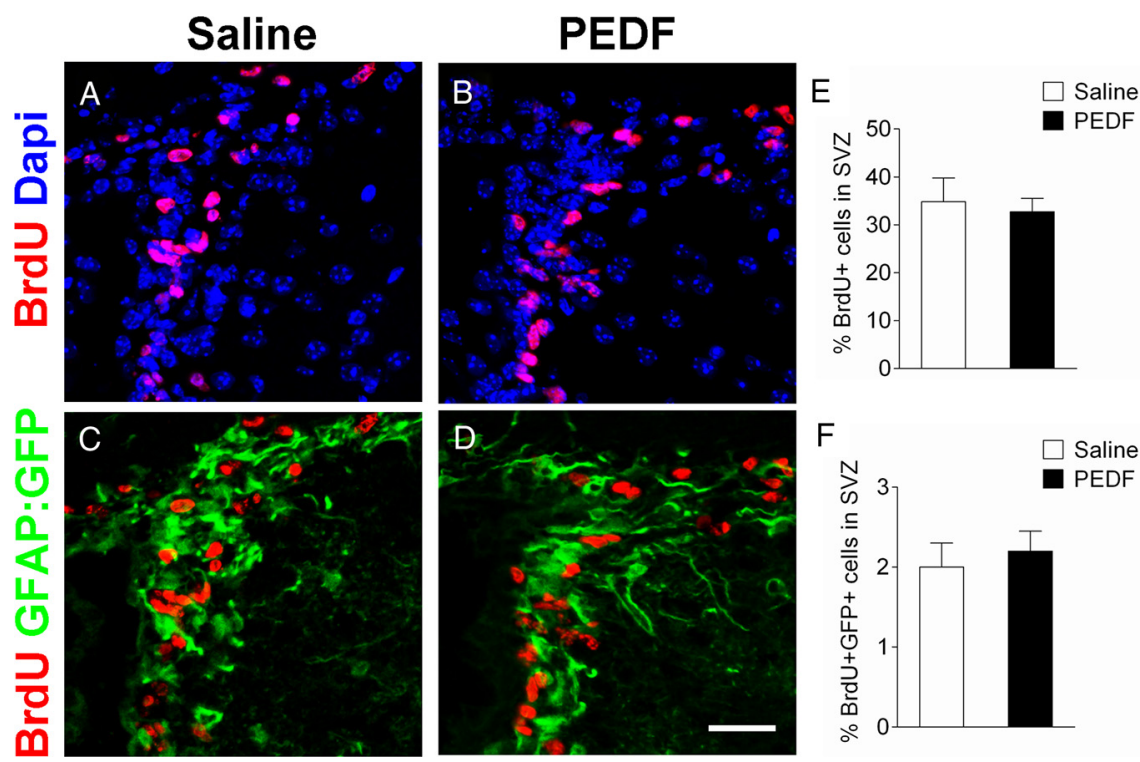

Figure 6. PEDF does notalter cell proliferation in the adultSVZ. Saline or PEDF (300 ng per day) was administered via osmotic pump into the lateral ventricle of GFAP:GFP transgenic mice for $7 \mathrm{~d}$. BrdU ( $100 \mathrm{mg} / \mathrm{kg}$ body weight, i.p.) was injected daily into the animals from day 5 to day 7. $A-\boldsymbol{D}$, Confocal images of coronal section of saline-and PEDF-infused SVZ immunostained for $\operatorname{BrdU}(\boldsymbol{A}, \boldsymbol{B})$ or BrdU and GFP $(\boldsymbol{C}, \boldsymbol{D})$. $\boldsymbol{E}$, $\boldsymbol{F}$, Quantification of BrdU-single positive $(\boldsymbol{E})$ and BrdU/GFP-double positive $(\boldsymbol{F})$ cells in the SVZ. Cell proliferation was not significantly different between saline- and PEDF-infused SVZ. Scale bar, $35 \mu \mathrm{m}$. Results are means \pm SEM ( $n=3$ brains).

PEDF promotes oligodendroglial production and maturation derived from cycling OPCs in the adult corpus callosum PEDFr immunoreactivity was also detected in corpus callosal Olig2 + oligodendroglial lineage cells (Fig. 4C-E) and GFAP:
GFP + astrocytes (Fig. $4 F-H$ ), suggesting possible PEDF actions on the corpus callosum. Previous studies have shown that OPCs in the adult brain proliferate, albeit at a much lower rate than in the newborn, and generate mature oligodendrocytes (Dawson et 
A
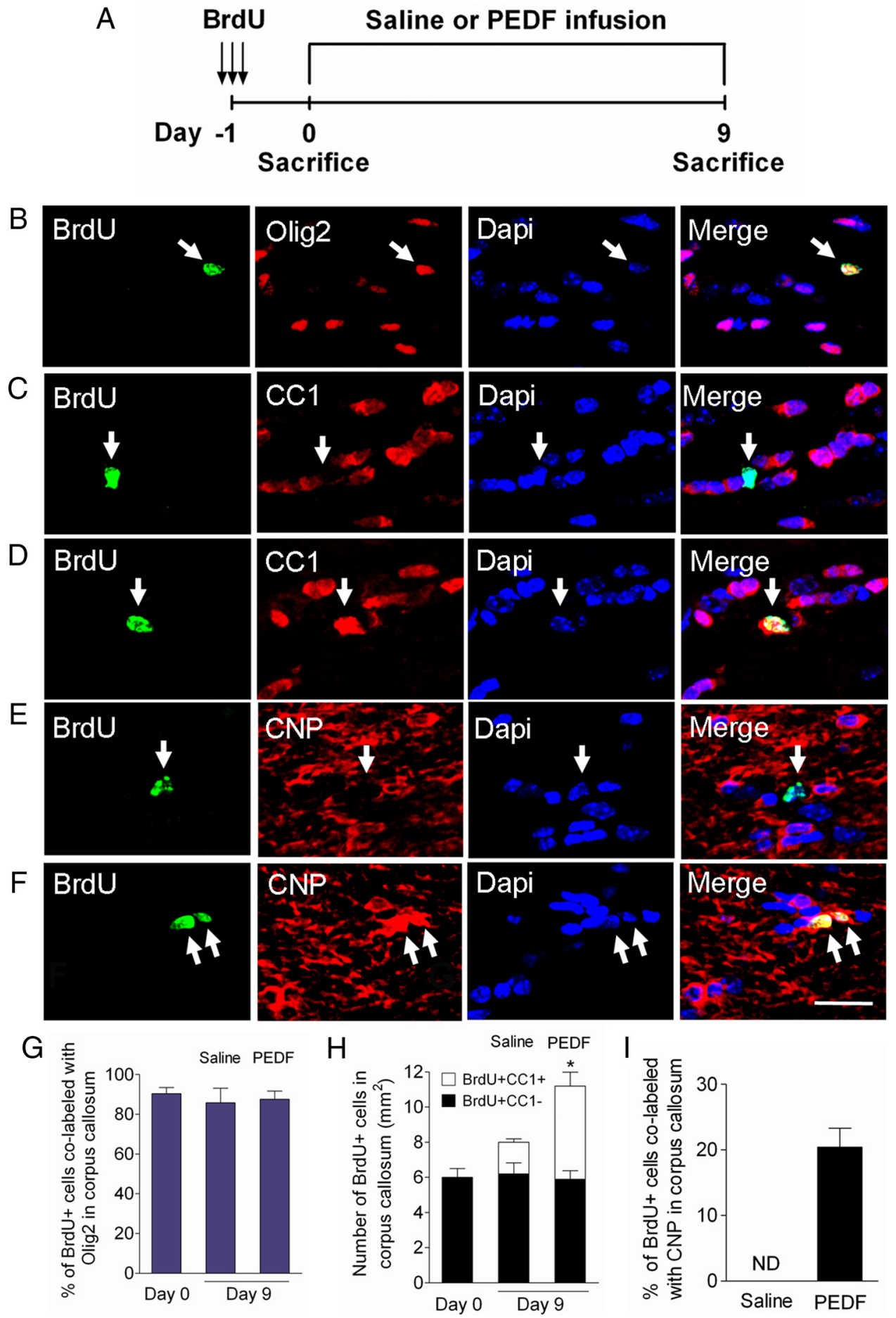

Figure 7. PEDF enhances oligodendrocyte production and maturation of cycling OPCs in the adult corpus callosum. $A$, Experimental design. Adult wild-type mice received three consecutive administrations of BrdU (100 mg/kg body weight, i.p.) at $6 \mathrm{~h}$ intervals to label cycling OPCs in the corpus callosum, followed by saline or PEDF ( $300 \mathrm{ng}$ per day) intracerebral infusion for $9 \mathrm{~d}$. B, C, Confocal images of cells

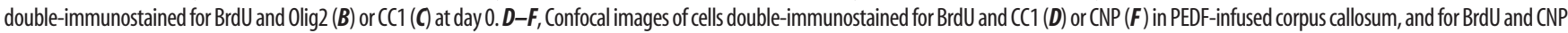
(E) in saline-infused corpus callosum at day 9. G, Percentages of BrdU + cells that were colabeled with Olig2 at day 0 and day 9 . The vast majority of cycling cells in the corpus callosum were 0 lig2 + . $\boldsymbol{H}$, Quantification for cells coimmunolabeled for BrdU and CC1, a marker for mature oligodendrocytes, in the corpus callosum at day 0 and day 9. At day 0, BrdU-labeled OPCs did not express CC1. By day 9, CC1+ mature oligodendrocytes had been produced from BrdU + OPCs after both saline and PEDF infusion, but significantly more with PEDF infusion. I, Percentages of BrdU + cells colabeled with CNP in saline- and PEDF-infused corpus callosum demonstrating that PEDF robustly promoted terminal maturation of newly born OPCS. ND, Not detected. $\boldsymbol{B}-\boldsymbol{F}$, Arrows indicate BrdU + cells coimmunostained with oligodendroglial markers. Scale bar, $35 \mu \mathrm{m}$. Results are means $\pm \operatorname{SEM}\left(n=3\right.$ brains). ${ }^{*} p<0.01$, an increase in the number of BrdU $+C C 1+$ cells in between saline-vs PEDF-infused corpus callosum at day 9 , Student's $t$ test.

al., 2003; Polito and Reynolds, 2005; Rivers et al., 2008). To determine the effects of PEDF infusion on OPCs in the adult corpus callosum, we administrated BrdU intraperitoneally to adult wildtype mice before $9 \mathrm{~d}$ of intracerebral infusion with saline or PEDF
(Fig. 7A, experimental design). At day 0 (i.e., $24 \mathrm{~h}$ after first $\mathrm{BrdU}$ injection), a small number of BrdU+ cells were present in the corpus callosum. Greater than $90 \%$ of these BrdU+ cells were also Olig2+ (Fig. $7 B, G$ ), but none expressed immunohistologi- 
A
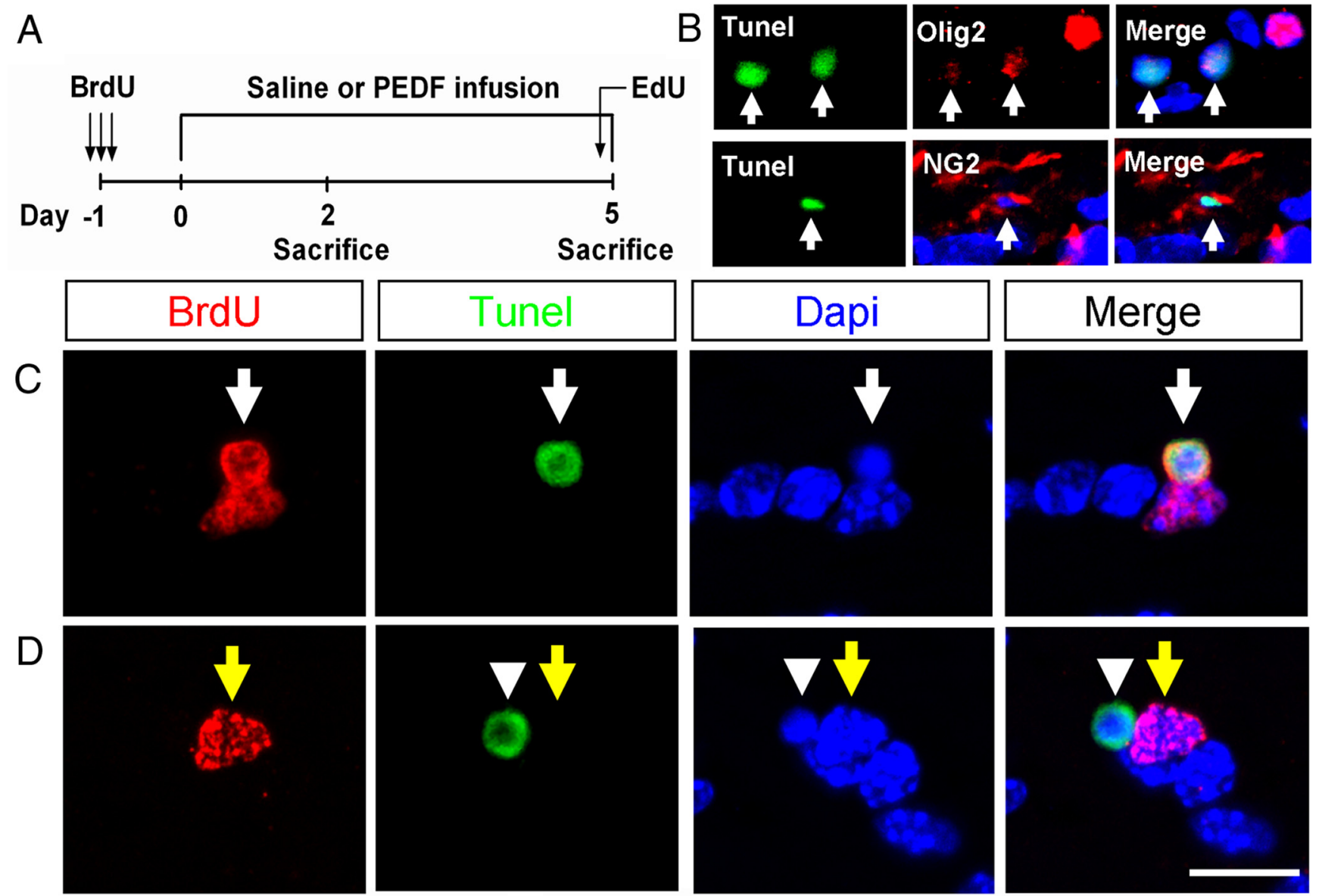

$E$
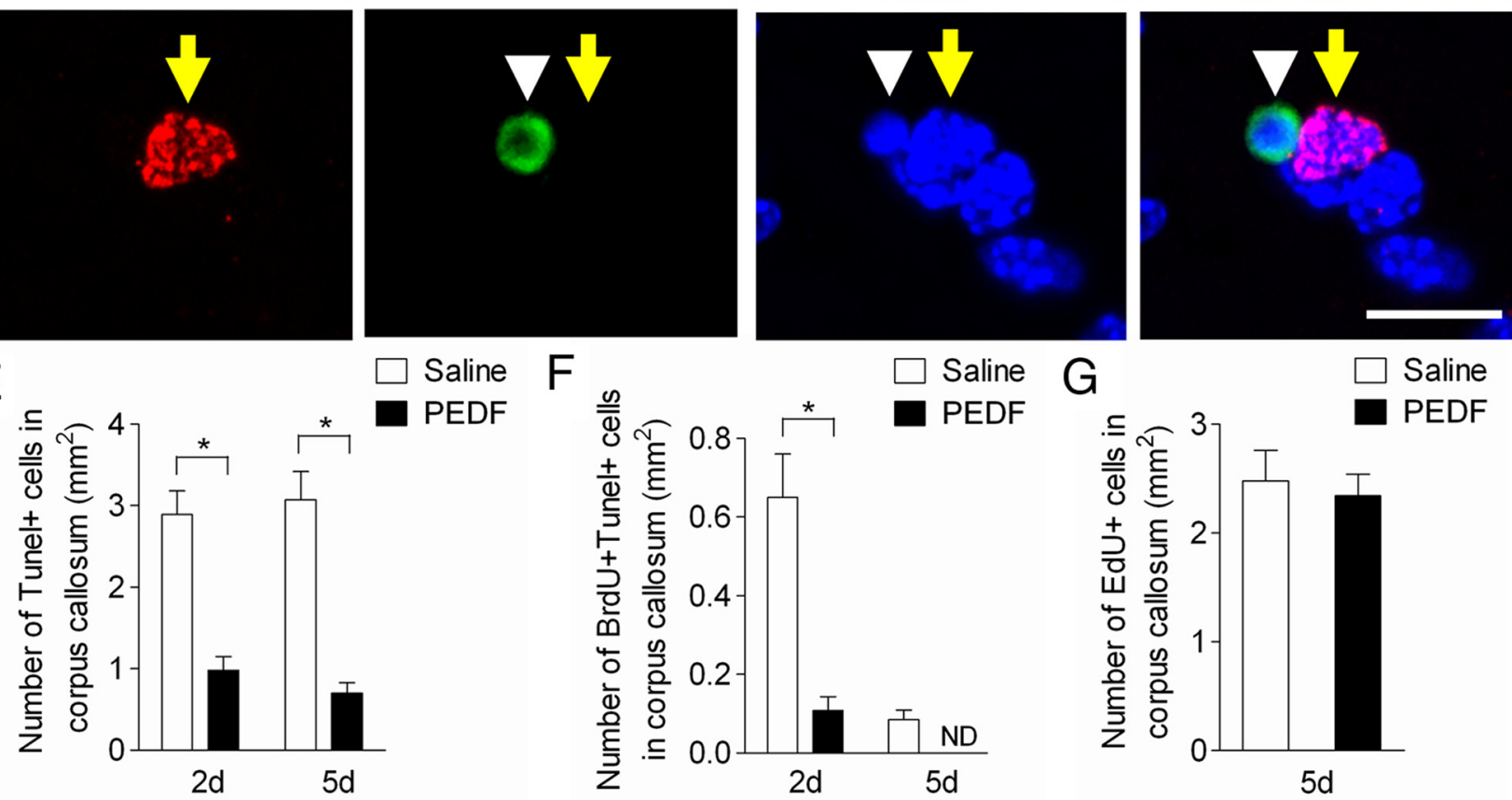

Figure 8. PEDFenhances cell survival in the adult corpus callosum. $\boldsymbol{A}$, Experimental design. Adult wild-type mice received three consecutive administrations of BrdU (100 mg/kg body weight, i.p.) at $6 \mathrm{~h}$ intervals to label cycling OPCs in the corpus callosum, followed by saline or PEDF ( $300 \mathrm{ng}$ per day) intracerebral infusion for 2 or $5 \mathrm{~d}$. At day 5 , EdU (100 mg/body weight, i.p.) was also injected into the animals $5 \mathrm{~h}$ before they were killed. $\boldsymbol{B}$, Confocal images of cells colabeled for TUNEL and 0lig2 or NG2 in saline-infused corpus callosum, showing oligodendroglial lineage cells undergoing apoptosis. C, D, Confocal images of cells double-assayed for BrdU and TUNEL in the saline (C)- or PEDF (D)-infused corpus callosum. $\boldsymbol{C}$, BrdU+/TUNEL+ cell is indicated by white arrows. $\boldsymbol{D}$, $\mathrm{BrdU}+/$ TUNEL - cell is indicated by yellow arrows. BrdU - /TUNEL + cell (arrowheads) confirms the absence of cross-reactivity between BrdU and TUNEL staining. $\boldsymbol{E}, \boldsymbol{F}$, Percentages of TUNEL + $(\boldsymbol{E})$ and BrdU +/TUNEL $+(\boldsymbol{F})$ cells in saline- or PEDF-infused corpus callosum at day 2 and 5 , indicating a potent cell survival effect of PEDF on the corpus callosal cells including newly born OPCS $(\boldsymbol{F}) . \mathbf{G}$, EdU incorporation assay indicating that PEDF did not significantly alter cell proliferation in the corpus callosum. ND, Not detected. Scale bar, $15 \mu \mathrm{m}$. Results are means \pm SEM ( $n=3$ brains). ${ }^{*} p<0.01$, Student's $t$ test.

cally detectible CC1, a marker for mature oligodendrocytes (Fig. $7 C, H$ ), indicating that they were immature oligodendroglial lineage cells, presumably OPCs. By day 9, the percentages of BrdU+ cells that were colabeled with Olig2 in the corpus callosum were similar in saline- and PEDF-infused mice, and did not differ from the results obtained at day 0 (Fig. 7G). We observed occasional $\mathrm{BrdU}+/ \mathrm{CC} 1+$ cells in the corpus callosum of the saline-infused mice at day 9 (Fig. $7 H$ ), indicating that some OPCs initially labeled with BrdU had differentiated into mature oligodendrocytes. Impor- tantly, the production of mature oligodendrocytes was robustly enhanced by PEDF infusion, as demonstrated by substantially greater numbers of BrdU+/CC1 + cells in PEDF-infused than in salineinfused corpus callosum (Fig. 7D,H). Furthermore, no BrdU+ cells were found to be immunoreactive for the myelin sheath protein $\mathrm{CNP}$ in saline-infused corpus callosum at this time-point (Fig. $7 E, I$ ), whereas $\sim 20 \%$ of BrdU+ cells expressed CNP in PEDFinfused corpus callosum (Fig. $7 F, I$ ), indicating accelerated terminal maturation by PEDF. 

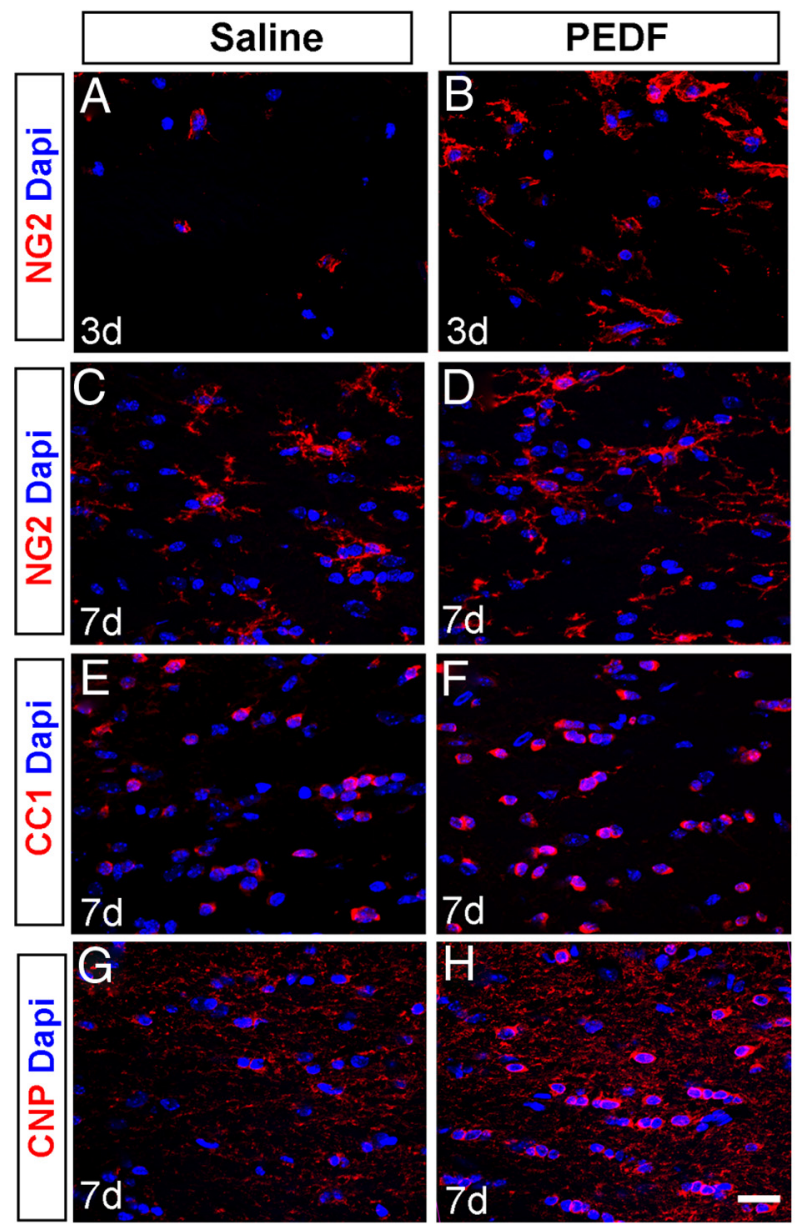

Figure 9. PEDF promotes oligodendroglial regeneration in lysolecithin-induced demyelinative corpus callosum. Administration of lysolecithin to adult corpus callosum to induce focal demyelination was followed by saline or PEDF (300 ng per day) infusion for 3 or $7 \mathrm{~d}$. $\boldsymbol{A}-\boldsymbol{H}$, Confocal images of cells in saline- or PEDF-infused corpus callosum immunolabeled with antibodies against NG2 $(\boldsymbol{A}-\boldsymbol{D}), \boldsymbol{C C}(\boldsymbol{E}, \boldsymbol{F})$, or CNP $(\boldsymbol{G}, \boldsymbol{H})$ at 3 or $7 \mathrm{dpl}$. Scale bars, $25 \mu \mathrm{m}$. $\boldsymbol{I}-\boldsymbol{L}, \mathrm{MBP}$ immunostaining of saline $(\boldsymbol{I}, \boldsymbol{K})$ - or PEDF $(\boldsymbol{J}, \boldsymbol{L})$-infused corpus callosum at 7 dpl. $\boldsymbol{K}, \boldsymbol{L}$, High-magnification images of the areas indicated by rectangles in $\boldsymbol{I}$ and $\boldsymbol{J}$, respectively. Scale bars, $50 \mu \mathrm{m} . \boldsymbol{M}, \boldsymbol{N}$, Quantification for NG2+ OPCs at 3 and $7 \mathrm{dpl}(\boldsymbol{M})$, and CC1 + and CNP + mature oligodendrocytes $(\boldsymbol{N})$ at $7 \mathrm{dpl}$. Note that PEDF infusion resulted in markedly higher numbers of NG2 + cells present in the lesional corpus callosum at 3 dpl, and substantially enhanced CNP + mature oligodendrocyte production and CNP immunoreactivity, and MBP-positive myelin levels at $7 \mathrm{dpl}$. CC, Corpus callosum; LV, lumen of lateral ventricles. Results are means \pm SEM ( $n=4$ brains). ${ }^{*} p<0.05$ and ${ }^{* *} p<0.01$, Student's $t$ test.

PEDF promotes oligodendroglial cell survival in the adult corpus callosum.

The observed increase in the number of BrdU $+/ C C 1+$ cells by PEDF infusion suggested the hypothesis that PEDF enhances survival of newly born OPCs in the corpus callosum. To test this hypothesis, we designed an experiment (Fig. 8A) in which BrdU was administered to wild-type adult mice, followed by saline or PEDF infusion for 2 or $5 \mathrm{~d}$, at the end of which time cells undergoing apoptosis were visualized by TUNEL assay. In addition, 5 ' -ethynyl-2' -deoxyuridine (EdU) was also administered $5 \mathrm{~h}$ before animals were killed at day 5 to determine cell proliferation in the corpus callosum. TUNEL + cells were detected in the corpus callosum of the saline-infused corpus callosum at day 2 and 5 albeit at very low density ( 2.9 and 3.0 cells per $\mathrm{mm}^{2}$, respectively; Fig. $8 E$ ). Some TUNEL + cells were also colabeled with BrdU+ (Fig. $8 \mathrm{~F}$ ), providing evidence for apoptosis of newly born OPCs. We detected occasional TUNEL + cells that were colabeled with Olig2 or NG2 in the corpus callosum (Fig. $8 B$ ), but in most instances we were unable to immunohistologically classify these apoptotic cells, presumably due to substantial cell degradation and loss of protein expression (Fig. $8 \mathrm{~B}$, weak residual Olig2 expressions in TUNEL + cells indicated by arrows). Notably, the frequencies of both total TUNEL+ (Fig. 8E) and BrdU+/ TUNEL+ (Fig. $8 F$ ) cells in the corpus callosum on both days 2 and 5 were sharply lower in the PEDF-infused mice than in the saline-infused controls. Overall, our data indicate that PEDF promotes cell survival in the adult corpus callosum, including survival of mitotically cycling OPCs. PEDF did not significantly modulate cell proliferation in the corpus callosum, as determined by EdU assay (Fig. 8G), providing further evidence for the lack of mitogenic activity by PEDF.

\section{PEDF accelerates oligodendroglial regeneration in the}

lysolecithin-induced corpus callosum demyelinative lesions After eliciting focal demyelinative lesions in the corpus callosum of the adult mice by lysolecithin injection (Jablonska et al., 2010), we infused saline or PEDF via osmotic pump into the lesion site for 3 or $7 \mathrm{~d}$. At $3 \mathrm{~d}$ postlesion (dpl), NG2 + OPCs were infrequent in the lesions of the saline-infused mice (Fig. 9A,M), but were present in substantially higher numbers in the lesions of the PEDF-infused mice (Fig. 9B, M). By $7 \mathrm{dpl}$, the density of lesional $\mathrm{NG} 2+\mathrm{OPCs}$ in the saline-infused controls had increased and became comparable to that in the PEDF-treated mice (Fig. $9 C, D, M$,$) . At this 7 \mathrm{~d}$ time-point, however, $\mathrm{CC} 1+$ mature oligo- 

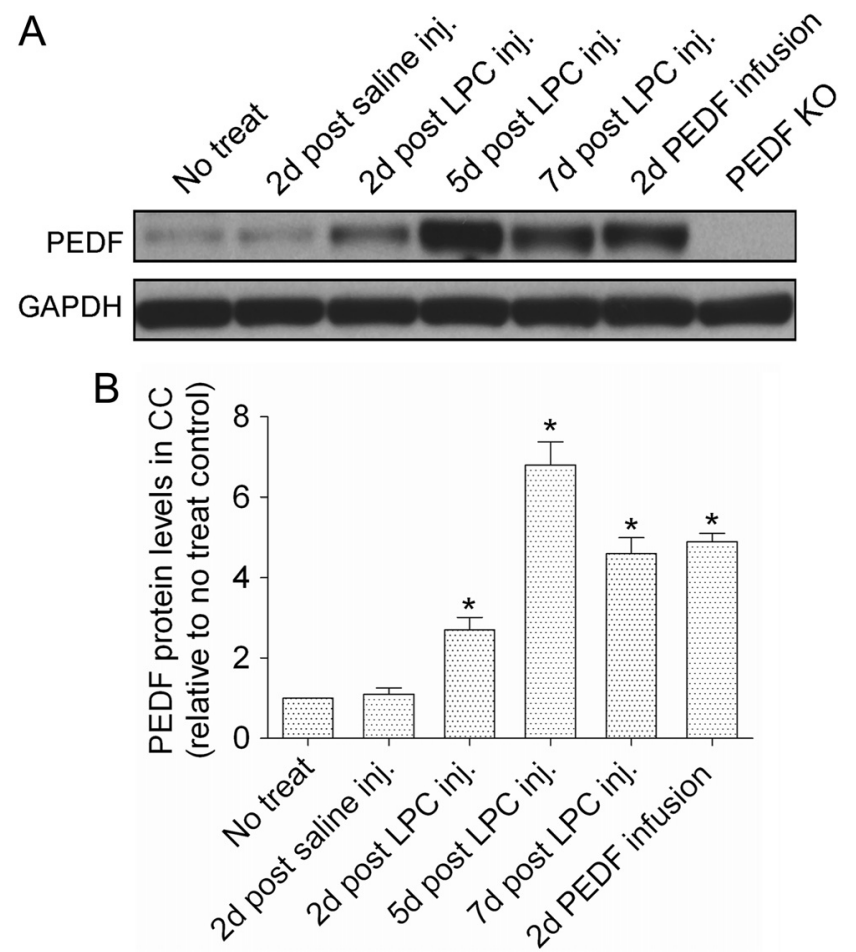

Figure 10. Regulation of PEDF protein expression in lysolecithin-induced demyelinative corpus callosum. Mice received no treatment, saline or lysolecithin (LPC) injections to corpus callosum (CC), or PEDF infusion (300 ng per day) to corpus callosum. Protein extracts from ipsilateral corpus callosum were analyzed for PEDF expression by Western blots. $\boldsymbol{A}$, Representative Western blot showing robust upregulation of PEDF expression in the corpus callosum after lysolecithin injection. Specificity of the PEDF antibody used for Western blotting was confirmed by the absence of immunoreactive PEDF in homozygous PEDF knock-out (KO) mice. $B$, Densitometric quantification demonstrated that PEDF contents were 2.7-, 6.7-, and 4.6-fold higher in lysolecithin-lesioned than intact corpus callosum on days 2, 5, and 7 post-lysolecithin injection, respectively. In nonlesioned mice, $2 \mathrm{~d}$ of intracerebral recombinant PEDF infusion raised corpus callosum PEDF content by 4.9 -fold. Results are means $\pm \operatorname{SEM}(n=3 \mathrm{mice} / \mathrm{point})$. ${ }^{*} p<0.001$ (Student's $t$ test), significantly elevated over level in intact corpus callosum.

dendrocytes were present at significantly higher density in the PEDF-infused than in the saline-infused corpus callosum (Fig. $9 E, F, N)$. Notably, by day 7 of infusion, PEDF treatment resulted in a marked increase in the number of CNP + mature oligodendrocytes (Fig. 9G, $H, N$ ) and, as judged by MBP immunohistology, remyelination (Fig. 9I-L). Moreover, CNP immunoreactivity was more robust with PEDF treatment (Fig. 9H) than in saline controls (Fig. 9G). Altogether, our results demonstrate that PEDF administration accelerates oligodendroglial regeneration in the lysolecithindemyelinated corpus callosum.

\section{Induction of endogenous PEDF in the corpus callosum in response to demyelinative injury}

Next, we compared PEDF expression in normal corpus callosum with that in corpus callosum after lysolecithin or saline injection. We also determined PEDF accumulation in nonlesioned corpus callosum under our intracerebral PEDF infusion paradigm (300 ng per day). As shown by Western blotting (Fig. 10A,B), there was a robust induction of PEDF after lysolecithin lesioning, but not after saline control injection. This post-lysolecithin induction was evident on day 2 , peaked on day 5 , and had partially subsided by day 7 postlesioning. Recombinant PEDF infusion into the nonlesioned corpus callosum for $2 \mathrm{~d}$ resulted in a substantial increase in corpus callosum PEDF content, an increment comparable to that present on day 7 post-lysolecithin lesioning.
No PEDF immunoreactivity was detected in corpus callosum extracts from PEDF-null mice (Doll et al., 2003), validating the specificity of the PEDF antibody used in our Western blot analyses. Together, these results suggest the hypothesis that postdemyelinative induction of endogenous PEDF synthesis contributes to regeneration of the oligodendroglial lineage and remyelination.

\section{Discussion}

PEDF has well characterized anti-angiogenic and neuroprotective actions (Bilak et al., 2002; Doll et al., 2003; Sanagi et al., 2010), and has been shown to promote self-renewal of mouse SVZ neural precursor cells (Ramírez-Castillejo et al., 2006; AndreuAgulló et al., 2009), but the effects of this protein on the oligodendroglial lineage have not previously been defined. In the present studies, PEDF receptor was found to be ubiquitously expressed in the SVZ and corpus callosum reflecting broad acting effects of PEDF on the germinal zone and the whiter matter. We demonstrate that PEDF enhances (1) oligodendroglial lineage induction of adult SVZ neural precursors both in vitro and in vivo, (2) oligodendrocyte formation and survival in the normal adult corpus callosum, and (3) oligodendroglial regeneration in corpus callosum focal demyelinative lesions.

Our initial observation that PEDF treatment during expansion of adult wild-type SVZ neurospheres augmented the number of NG2 + cells prompted us to investigate the oligodendrogenic effects of PEDF on SVZ GFAP + neural precursors. Using neurosphere cultures prepared from the SVZ of adult GFAP: GFP transgenic mice, we showed that PEDF treatment enhanced the proportion of GFAP:GFP + neurosphere cells coexpressing NG2 without altering proliferation, suggesting a role for PEDF in promoting oligodendroglial specification of GFAP + neural precursors. This notion was further supported by our finding that the oligodendrogenic effects (i.e., enhanced oligodendroglial transcription factor expressions and oligodendroglial differentiation, Fig. 2) of PEDF were demonstrable in neurospheres derived from GFAP + NG2- (i.e., unspecified toward oligodendroglial lineage) neural precursors. Interestingly, these PEDF effects were also evident in GFAP $+\mathrm{NG} 2+$ precursor-derived neurospheres, suggesting that PEDF is an oligodendroglial morphogen acting on overall GFAP+ neural precursor populations. In our neurosphere culture studies, however, we did not address the oligodendrogenic effect of PEDF on SVZ GFAP:GFP- populations including neuroblasts because (1) the neurospheres contained extremely few early neuronal lineage cells (Fig. 1D) and (2) FACS-purified single GFAP:GFP - cells substantially lacked neurosphere forming capability (data not shown).

Our analyses of the adult SVZ after PEDF infusion using osmotic pumps further demonstrated the effects of PEDF on enhancing oligodendroglial induction in both SVZ GFAP + cells and DCX + neuroblasts. It has previously been reported that a subset of GFAP + cells in adult mouse SVZ expresses PDGFr $\alpha$ (Jackson et al., 2006), suggesting the presence of SVZ GFAP+ neural precursor cells with early specification toward the oligodendroglial lineage. In contrast, Chojnacki et al. (2011) reported the absence of GFAP and PDGFr $\alpha$ double-positive cells in the adult mouse SVZ. Employing GFAP:GFP transgenic mice allowed us to visualize GFAP + cells and to firmly discriminate between GFAP + and PDGFr $\alpha+$ cells in the SVZ. We are reasonably confident that PDGFr $\alpha+$ immunoreactivity in the SVZ is expressed by some GFAP + cells, and observed that intraventricular PEDF infusion significantly augmented proportions of SVZ GFAP + cells colabeled with PDGFr $\alpha$ and other oligodendroglial lineage markers. Our results therefore indicate that increasing 
PEDF level stimulates the prevalence of these oligodendrogenic GFAP + cells in the adult SVZ.

Our SVZ findings are not fully in line with those previously reported by another group (Ramírez-Castillejo et al., 2006; Andreu-Agulló et al., 2009), who, while not commenting on oligodendrotrophic effects of PEDF, observed that PEDF induced self-renewal and multipotency of adult SVZ GFAP + neural precursor cells. These discrepancies may be at least in part attributable to two factors: (1) they infused less than one tenth the concentration of PEDF that we used; and (2) they appear to have focused on the ventral lining of the lateral ventricles, whereas we analyzed the dorsal SVZ, which is in close proximity to the overlying corpus callosum and hence may be more intrinsically oligodendrogenic.

It should be also noted that unlike in the adult corpus callosum, where all PDGFr $\alpha+$ OPCs were colabeled for NG2 (Rivers et al., 2008), PDGFr $\alpha$ and NG2 expressions showed different patterns in the adult SVZ. For example, the percentage of PDGFr $\alpha+$ cells was substantially higher than that of NG2 + cells in the saline-infused control SVZ. Moreover, the SVZ PDGFr $\alpha+$ cells were mostly GFP + whereas the SVZ NG2 + cells largely lacked GFP expression. We reason that PDGFra + and NG2+ cells are at different states of oligodendroglial lineage in adult SVZ. Similar to NG2, Olig2+ and Sox10+ cells were also present at lower densities than PDGFr $\alpha+$ cells in the SVZ and were also mostly GFP-. These findings suggest that PDGFra + cells are likely earlier in oligodendroglial lineage than $\mathrm{NG} 2+$, Olig2 or Sox10+ cells in the adult SVZ.

Jablonska et al. (2010) have reported oligodendroglial lineage induction in SVZ neuroblasts after lysolecithin-induced focal demyelination in the adult corpus callosum. Our findings that (1) PEDF receptor is expressed by SVZ DCX + neuroblasts and (2) PEDF infusion resulted in an induction of DCX $+/$ Sox $10+$ cells in the adult SVZ, suggest that PEDF infusion can potentiate oligodendroglial lineage plasticity of SVZ neuroblasts even under nondemyelinating condition. In sum, our data indicate that PEDF stimulates SVZ oligodendrogenesis in at least two ways, via (1) enhancing oligodendroglial specification of GFAP:GFP+ cells, thereby increasing the number of oligodendrogenic GFAP: GFP + cells and (2) inducing specification of DCX + neuroblasts to the oligodendroglial lineage.

We also determined that PEDF infusion enhanced differentiation of mitotically labeled OPCs to mature oligodendroglia, as clearly demonstrated by robust induction of $\mathrm{BrdU}+/ \mathrm{CNP}+$ cells. Rivers et al. (2008) previously documented continuous addition of oligodendroglial lineage cells derived from PDGFr $\alpha+$ OPCs in the adult corpus callosum by using PDGFr $\alpha$-ER ${ }^{\mathrm{T} 2} /$ Rosa-EYFP transgenic mice. Our data are in line with that prior result, and add to it by demonstrating that PEDF potentiates the production of mature oligodendroglial cells by cycling OPCs in the adult corpus callosum. While a survival effect of PEDF on neuronal cells was previously demonstrated in vitro and in vivo (Yabe et al., 2005; Sanagi et al., 2010), such actions have never been documented in the oligodendroglial lineage. During development, OPCs actively proliferate and considerable programmed cell death of these proliferating OPCs occurs (Barres et al., 1992, 1993). In the normal adult corpus callosum, we found that some mitotically cycling OPCs also undergo apoptosis, and that PEDF infusion robustly enhances the survival of these newly born OPCs. This presumably contributed to the increased production of BrdU $+/ C C 1+$ mature oligodendrocytes we observed at day 9 (Fig. $7 H$ ). By performing EdU incorporation assays, we ruled out enhanced OPC proliferation as another possible cause for PEDF-induced augmentation of $\mathrm{CC} 1+$ cell production. Altogether, our studies indicate that PEDF promotes both maturation and survival of OPCs in the normal adult corpus callosum.

We also evaluated the effects of PEDF infusion on regeneration of the oligodendroglial lineage after lysolecithin-elicited focal corpus callosum demyelination, primarily focusing on early postlesion phases (i.e., 3 and $7 \mathrm{dpl}$ ). PEDF-elicited enhancement of oligodendroglial regeneration was evident by increased (1) densities of lesional CC1 + and CNP+ oligodendrocytes, and (2) MBP immunoreactivity with PEDF treatment at $7 \mathrm{dpl}$. Notably, repopulation of lesions with NG2 + OPCs was greater with PEDF treatment than in the saline controls at $3 \mathrm{dpl}$ whereas the numbers of NG2+ OPCs in the corpus callosum of PEDF-treated and control mice were comparable by $7 \mathrm{dpl}$, suggesting a role for PEDF in promoting early OPC recruitment to the lesion. To fully elucidate mechanisms underlying PEDF-mediated myelin repair will require additional studies that determine the relative contributions of: (1) increased specification of SVZ cells (i.e., GFAP+ neural precursors and neuroblasts) to the oligodendroglial lineage; (2) increased survival of newly formed OPCs; and (3) accelerated terminal differentiation of OPCs, to this enhancing effect of PEDF infusion on post-lysolecithin corpus callosum oligodendroglial regeneration.

To evaluate the possibility that endogenously synthesized PEDF enhances oligodendroglial lineage regeneration and remyelination, we compared levels of PEDF in intact versus lysolecithin-demyelinated corpus callosum, and demonstrated substantial elevations in corpus callosum PEDF content during the first week post-lysolecithin lesioning. In mice infused with saline, rather than with recombinant PEDF, this PEDF elevation was temporally correlated with the recruitment of NG2+ OPCs and CC1 + oligodendrocytes to the demyelinated lesions (Fig. 9). Lesional repopulation with OPCs and oligodendroglia, and remyelination, were accelerated in mice given recombinant PEDF infusions, thus suggesting that the oligodendrotrophic and remyelinative effects of endogenous PEDF had been reinforced by the lesional administration of exogenous PEDF.

In conclusion, we have documented oligodendrotrophic effects of PEDF on SVZ neural progenitors and corpus callosum OPCs in the adult CNS. Corpus callosum PEDF expression is elevated following lysolecithin-induced demyelination, and infusion of the demyelinated lesions with recombinant PEDF accelerates repopulation by OPCs and oligodendroglia, and remyelination. These results provide a rationale for trials of PEDF therapy in demyelinative diseases.

\section{References}

Aguirre A, Gallo V (2004) Postnatal neurogenesis and gliogenesis in the olfactory bulb from NG2-expressing progenitors of the subventricular zone. J Neurosci 24:10530-10541.

Aguirre A, Rubio ME, Gallo V (2010) Notch and EGFR pathway interaction regulates neural stem cell number and self-renewal. Nature 467:323-327.

Andreu-Agulló C, Morante-Redolat JM, Delgado AC, Fariñas I (2009) Vascular niche factor PEDF modulates Notch-dependent stemness in the adult subependymal zone. Nat Neurosci 12:1514-1523.

Barres BA, Hart IK, Coles HS, Burne JF, Voyvodic JT, Richardson WD, Raff MC (1992) Cell death and control of cell survival in the oligodendrocyte lineage. Cell 70:31-46.

Barres BA, Schmid R, Sendnter M, Raff MC (1993) Multiple extracellular signals are required for long-term oligodendrocyte survival. Development 118:283-295.

Bilak MM, Becerra SP, Vincent AM, Moss BH, Aymerich MS, Kuncl RW (2002) Identification of the neuroprotective molecular region of pig- 
ment epithelium-derived factor and its binding sites on motor neurons. J Neurosci 22:9378-9386.

Brown JP, Couillard-Després S, Cooper-Kuhn CM, Winkler J, Aigner L, Kuhn HG (2003) Transient expression of doublecortin during adult neurogenesis. J Comp Neurol 467:1-10.

Chojnacki A, Mak G, Weiss S (2011) PDGFRalpha expression distinguishes GFAP-expressing neural stem cells from PDGF-responsive neural precursors in the adult periventricular area. J Neurosci 31:9503-9512.

Danilov AI, Gomes-Leal W, Ahlenius H, Kokaia Z, Carlemalm E, Lindvall O (2009) Ultrastructural and antigenic properties of neural stem cells and their progeny in adult rat subventricular zone. Glia 57:136-152.

Dawson MR, Polito A, Levine JM, Reynolds R (2003) NG2-expressing glial progenitor cells: an abundant and widespread population of cycling cells in the adult rat CNS. Mol Cell Neurosci 24:476-488.

Doetsch F, García-Verdugo JM, Alvarez-Buylla A (1997) Cellular composition and three-dimensional organization of the subventricular germinal zone in the adult mammalian brain. J Neurosci 17:5046-5061.

Doll JA, Stellmach VM, Bouck NP, Bergh ARJ, Lee C, Abramson LP, Cornwell ML, Pins MR, Borensztajn J, Crawford SE (2003) Pigment epitheliumderived factor regulates the vasculature and mass of the prostate and pancreas. Nat Med 9:774-780.

Ek ET, Dass CR, Choong PF (2006) PEDF: a potential molecular therapeutic target with multiple anti-cancer activities. Trends Mol Med 12:497-502.

Finzsch M, Stolt CC, Lommes P, Wegner M (2008) Sox9 and Sox10 influence survival and migration of oligodendrocyte precursors in the spinal cord by regulating PDGF receptor alpha expression. Development 135:637-646.

Frederiksen K, McKay RD (1988) Proliferation and differentiation of rat neuroepithelial precursor cells in vivo. J Neurosci 8:1144-1151.

Garcia AD, Doan NB, Imura T, Bush TG, Sofroniew MV (2004) GFAPexpressing progenitors are the principal source of constitutive neurogenesis in adult mouse forebrain. Nat Neurosci 7:1233-1241.

Gonzalez-Perez O, Romero-Rodriguez R, Soriano-Navarro M, GarciaVerdugo JM, Alvarez-Buylla A (2009) Epidermal growth factor induces the progeny of subventricular zone type B cells to migrate and differentiate into oligodendrocytes. Stem Cells 27:2032-2043.

Jablonska B, Aguirre A, Raymond M, Szabo G, Kitabatake Y, Sailor KA, Ming GL, Song H, Gallo V (2010) Chordin-induced lineage plasticity of adult SVZ neuroblasts after demyelination. Nat Neurosci 13:541-550.

Jackson EL, Garcia-Verdugo JM, Gil-Perotin S, Roy M, Quinones-Hinojosa A, VandenBerg S, Alvarez-Buylla A (2006) PDGFR alpha-positive B cells are neural stem cells in the adult SVZ that form glioma-like growths in response to increased PDGF signaling. Neuron 51:187-199.

Lagace DC, Whitman MC, Noonan MA, Ables JL, DeCarolis NA, Arguello AA, Donovan MH, Fischer SJ, Farnbauch LA, Beech RD, DiLeone RJ, Greer CA, Mandyam CD, Eisch AJ (2007) Dynamic contribution of nestin-expressing stem cells to adult neurogenesis. J Neurosci 27:1262312629.

Lu QR, Cai L, Rowitch D, Cepko CL, Stiles CD (2001) Ectopic expression of Olig1 promotes oligodendrocyte formation and reduces neuronal survival in developing mouse cortex. Nat Neurosci 4:973-974.

Menn B, Garcia-Verdugo JM, Yaschine C, Gonzalez-Perez O, Rowitch D, Alvarez-Buylla A (2006) Origin of oligodendrocytes in the subventricular zone of the adult brain. J Neurosci 26:7907-7918.

Morshead CM, Garcia AD, Sofroniew MV, van Der Kooy D (2003) The ablation of glial fibrillary acidic protein-positive cells from the adult central nervous system results in the loss of forebrain neural stem cells but not retinal stem cells. Eur J Neurosci 18:76-84.
Notari L, Baladron V, Aroca-Aguilar JD, Balko N, Heredia R, Meyer C, Notario PM, Saravanamuthu S, Nueda ML, Sanchez-Sanchez F, Escribano J, Laborda J, Becerra SP (2006) Identification of a lipase-linked cell membrane receptor for pigment epithelium-derived factor. J Biol Chem 281:38022-38037.

Pastrana E, Cheng LC, Doetsch F (2009) Simultaneous prospective purification of adult subventricular zone neural stem cells and their progeny. Proc Natl Acad Sci U S A 106:6387-6392.

Platel JC, Gordon V, Heintz T, Bordey A (2009) GFAP-GFP neural progenitors are antigenically homogeneous and anchored in their enclosed mosaic niche. Glia 57:66-78.

Polito A, Reynolds R (2005) NG2-expressing cells as oligodendrocyte progenitors in the normal and demyelinated adult central nervous system. J Anat 207:707-716.

Pozniak CD, Langseth AJ, Dijkgraaf GJ, Choe Y, Werb Z, Pleasure SJ (2010) Sox10 directs neural stem cells toward the oligodendrocyte lineage by decreasing Suppressor of Fused expression. Proc Natl Acad Sci U S A 107:21795-21800.

Ramírez-Castillejo C, Sánchez-Sánchez F, Andreu-Agulló C, Ferrón SR, Aroca-Aguilar JD, Sánchez P, Mira H, Escribano J, Fariñas I (2006) Pigment epithelium-derived factor is a niche signal for neural stem cell renewal. Nat Neurosci 9:331-339.

Rivers LE, Young KM, Rizzi M, Jamen F, Psachoulia K, Wade A, Kessaris N, Richardson WD (2008) PDGFRA/NG2 glia generate myelinating oligodendrocytes and piriform projection neurons in adult mice. Nat Neurosci 11:1392-1401.

Sanagi T, Yabe T, Yamada H (2007) Changes in pigment epitheliumderived factor expression following kainic acid induced cerebellar lesion in rat. Neurosci Lett 424:66-71.

Sanagi T, Yabe T, Yamada H (2010) Adenoviral gene delivery of pigment epithelium-derived factor protects striatal neurons from quinolinic acidinduced excitotoxicity. J Neuropathol Exp Neurol 69:224-233.

Shen Q, Wang Y, Kokovay E, Lin G, Chuang SM, Goderie SK, Roysam B, Temple S (2008) Adult SVZ stem cells lie in a vascular niche: a quantitative analysis of niche cell-cell interactions. Cell Stem Cell 3:289-300.

Sohn J, Natale J, Chew LJ, Belachew S, Cheng Y, Aguirre A, Lytle J, NaitOumesmar B, Kerninon C, Kanai-Azuma M, Kanai Y, Gallo V (2006) Identification of Sox17 as a transcription factor that regulates oligodendrocyte development. J Neurosci 26:9722-9735.

Tombran-Tink J, Barnstable CJ (2003) PEDF: a multifaceted neurotrophic factor. Nat Rev Neurosci 4:628-636.

Yabe T, Kanemitsu K, Sanagi T, Schwartz JP, Yamada H (2005) Pigment epithelium-derived factor induces pro-survival genes through cyclic AMP-responsive element binding protein and nuclear factor kappa B activation in rat cultured cerebellar granule cells: implication for its neuroprotective effect. Neuroscience 133:691-700.

Yasuda T, Fukuda-Tani M, Nihira T, Wada K, Hattori N, Mizuno Y, Mochizuki H (2007) Correlation between levels of pigment epitheliumderived factor and vascular endothelial growth factor in the striatum of patients with Parkinson's disease. Exp Neurol 206:308-317.

Zhou Q, Choi G, Anderson DJ (2001) The bHLH transcription factor Olig2 promotes oligodendrocyte differentiation in collaboration with $\mathrm{Nkx} 2.2$. Neuron 31:791-807.

Zhuo L, Sun B, Zhang CL, Fine A, Chiu SY, Messing A (1997) Live astrocytes visualized by green fluorescent protein in transgenic mice. Dev Biol 187: $36-42$. 